\title{
Antipsychotic-Induced Dopamine Supersensitivity Psychosis: Pharmacology, Criteria, and Therapy
}

\author{
Guy Chouinard $^{\mathrm{a}, \mathrm{b}, \mathrm{g}}$ Anne-Noël Samaha ${ }^{c, d}$ Virginie-Anne Chouinard ${ }^{\mathrm{e}} \mathrm{f}$

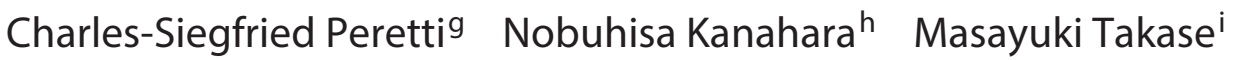 \\ Masaomi lyo ${ }^{\text {h, i }}$ \\ ${ }^{a}$ Clinical Pharmacology and Toxicology Program, McGill University Montreal, and ${ }^{b}$ University Mental Health \\ Institute of Montreal, University of Montreal, ' Department of Pharmacology and Physiology, and d Central \\ Nervous System Research Group (GRSNC), Faculty of Medicine, University of Montreal, Montreal, QC, Canada; \\ e Psychotic Disorders Division, McLean Hospital, Belmont, MA, and ${ }^{\mathrm{f}}$ Department of Psychiatry, Harvard Medical \\ School, Boston, MA, USA; ${ }^{9}$ Department of Psychiatry, Saint-Antoine University Hospital, Université Pierre et

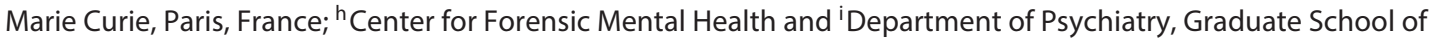 \\ Medicine, Chiba University, Chiba, Japan
}

\section{Keywords}

Antipsychotics · Drug-induced psychoses - Rebound . Antipsychotic-induced psychosis - Tardive dyskinesia . Supersensitivity psychosis - Dopamine supersensitivity psychosis · Dopamine $D_{2}$ receptor supersensitivity .

Schizophrenia

\begin{abstract}
The first-line treatment for psychotic disorders remains antipsychotic drugs with receptor antagonist properties at $\mathrm{D}_{2}$ like dopamine receptors. However, long-term administration of antipsychotics can upregulate $D_{2}$ receptors and produce receptor supersensitivity manifested by behavioral supersensitivity to dopamine stimulation in animals, and movement disorders and supersensitivity psychosis (SP) in patients. Antipsychotic-induced SP was first described as the emergence of psychotic symptoms with tardive dyskinesia (TD) and a fall in prolactin levels following drug discontinuation. In the era of first-generation antipsychotics, 4 clinical features characterized drug-induced SP: rapid relapse after drug discontinuation/dose reduction/switch of antipsychot-
\end{abstract}

\section{KARGER}

(C) 2017 S. Karger AG, Basel

E-Mail karger@karger.com

www.karger.com/pps ics, tolerance to previously observed therapeutic effects, cooccurring TD, and psychotic exacerbation by life stressors. We review 3 recent studies on the prevalence rates of SP, and the link to treatment resistance and psychotic relapse in the era of second-generation antipsychotics (risperidone, paliperidone, perospirone, and long-acting injectable risperidone, olanzapine, quetiapine, and aripiprazole). These studies show that the prevalence rates of SP remain high in schizophrenia (30\%) and higher (70\%) in treatment-resistant schizophrenia. We then present neurobehavioral findings on antipsychotic-induced supersensitivity to dopamine from animal studies. Next, we propose criteria for SP, which describe psychotic symptoms and co-occurring movement disorders more precisely. Detection of mild/borderline druginduced movement disorders permits early recognition of overblockade of $D_{2}$ receptors, responsible for SP and TD. Finally, we describe 3 antipsychotic withdrawal syndromes, similar to those seen with other CNS drugs, and we propose approaches to treat, potentially prevent, or temporarily manage SP.

(c) 2017 S. Karger AG, Basel

Prof. Dr. Guy Chouinard

416-1, rue McGill

Montréal, QC H2Y 4A3 (Canada)

E-Mail guy.chouinard@ umontreal.ca

Dr. Virginie-Anne Chouinard

McLean Hospital

115 Mill Street, Mailstop 108

Belmont, MA 02421 (USA)

E-Mail vchouinard@ mclean.harvard.edu 


\section{Introduction}

Antipsychotic medications, whether first or second generation, remain the standard drug treatment for schizophrenia and schizoaffective and psychotic disorders [1-4], including their relapse prevention [5]. All currently used antipsychotics interact with the dopamine $D_{2}\left(D_{2}\right)$ receptor to reduce dopamine-mediated signaling. However, long-term administration of antipsychotics can increase brain dopamine binding sites [6, 7] and produce behavioral supersensitivity to dopamine receptor stimulation in animals [6-13]. In humans, behavioral supersensitivity to dopamine [14-18] can be expressed through supersensitivity psychosis (SP) [19] and movement disorders such as tardive dyskinesia (TD) [20]. Moreover, drug-induced SP may superimpose on dopamine supersensitivity already present in schizophrenia [16, 21-23]. In 1978/1979, Chouinard and Jones $[21,22]$ proposed that a decrease in functional brain dopamine leads to dopamine supersensitivity, compensatory dopamine overactivity, and psychotic positive symptoms in schizophrenia. Our group at McGill [23] found elevated DOPA decarboxylase activity in living brain of patients with psychosis including drugnaïve patients with schizophrenia, which was compatible with our proposed hypothesis of a decrease in functional dopamine $[21,22]$. An increase in $\mathrm{D}_{2}$ receptor occupancy by dopamine can occur in first-episode drugnaïve schizophrenia and in previously treated patients experiencing an untreated exacerbation of psychosis [24]. Seeman et al. $[25,26]$ proposed that in several regions of the brain an increase in the number of $\mathrm{D}_{2}$ receptors in the high-affinity state $\left(\mathrm{D}_{2}{ }^{\mathrm{High}}\right)$ for dopamine is the pharmacological basis of antipsychotic-induced SP and idiopathic psychosis [16]. The $\mathrm{D}_{2}$ receptor, like other receptors, can exist in either a high- or low-affinity state for dopamine and dopamine agonists $\left(\mathrm{D}_{2}{ }^{\text {High }}\right.$ or $\mathrm{D}_{2}{ }^{\text {Low }}$, respectively). George et al. [27] showed that the $\mathrm{D}_{2}{ }^{\text {High }}$ state is the functional state of the dopamine $\mathrm{D}_{2}$ receptor. Up to $90 \%$ of dopamine depletion generally causes only minimal psychological and motor changes in patients with Parkinson disease. Considering this nonlinearity of function within the nervous system, a 2or 3-fold increase in $\mathrm{D}_{2}{ }^{\text {High }}$ receptors can be expected to cause major alterations in behavior. At least 25 different animal models of behavioral dopamine supersensitivity support this view $[25,26]$.

In 1978, Chouinard et al. [28] described SP as a psychotic exacerbation that occurred with emergent dyskinesia and a fall in plasma prolactin levels following anti- psychotic discontinuation in chronically treated patients during double-blind controlled studies. Davis and Rosenberg [29] considered SP as a limbic equivalent of TD. Later, Chouinard and Jones [30] described clinical characteristics of SP and proposed diagnostic criteria [14]. Patients with SP show a rapid relapse of positive symptoms upon drug discontinuation/dose reduction, appearance of new or more severe psychotic symptoms, tolerance to previously observed therapeutic effects, drug-induced movement disorders [31], and psychotic exacerbation by stress $[1,14]$. In the era of first-generation antipsychotics (FGAs), these clinical features were further described $[1,14,19]$, and different mechanisms were proposed $[4,15,20]$. More recently, considering that the relationship between SP and dopamine was sufficiently established, Iyo et al. [4] proposed the term dopamine SP and an increase in $\mathrm{D}_{2}$ receptor density and/or function secondary to $\mathrm{D}_{2}$ blockade as the underlying mechanism. These $\mathrm{D}_{2}$ receptor changes require an increase in antipsychotic concentrations to maintain therapeutic effects, so as to compensate for the increased receptor availability [4]. Therapeutic drug tolerance then occurs $[14,28,30]$. High doses and high plasma antipsychotic levels become necessary to control psychotic symptoms [19].

Second-generation antipsychotics (SGAs) have decreased the prevalence of drug-induced movement disorders including TD [1], but concerns [1] and questions have remained about SP $[32,33]$. Three recent studies [34-36], including a total of 505 schizophrenic patients treated with SGAs, have found that the prevalence rates of SP remain high $(30 \%)$ in schizophrenia $(n=261)$ and higher (70\%) in treatment-resistant (TR) schizophrenia $(n=241)$. Using TD to identify SP, Fallon and Dursun [37] and Fallon et al. [38] found that SP could be the cause of relapse in $30-40 \%$ of schizophrenic patients. Antipsychotics with the potential to induce parkinsonism and other movement disorders may cause SP [1]. However, the reverse is not necessarily true. For instance, quetiapine [39] and clozapine [33, 40] can induce SP without producing overt or detectable drug-induced movement disorders.

We first review pharmacological mechanisms linking SP to a compensatory increase in $\mathrm{D}_{2}$ receptor density/ biological function. We then describe the clinical characteristics and consequences of SP. Finally, we propose diagnostic criteria for antipsychotic withdrawal syndromes, in line with withdrawal syndromes induced by other CNS drugs $[1,41]$, and we give guidelines for the treatment and prevention of SP based on the available evidence.
190

Psychother Psychosom 2017;86:189-219 DOI: $10.1159 / 000477313$
Chouinard/Samaha/Chouinard/Peretti/ Kanahara/Takase/Iyo 


\section{Pharmacological Mechanisms by Which Antipsychotics Potentially Increase $D_{2}$ Receptor Density and/or Function}

Long-term administration of antipsychotics, through $\mathrm{D}_{2}$ receptor blockade, increases $\mathrm{D}_{2}$ receptor density in the striatum [42-45], either through an increase in $\mathrm{D}_{2}$ receptor synthesis, a decrease in $\mathrm{D}_{2}$ receptor degradation, or both. The increase is similar to that induced by nigrostriatal lesions [7]. In animal models, increased $\mathrm{D}_{2}$ density is associated with behavioral supersensitivity to dopamine stimulation manifested by TD-like symptoms $[42,43]$, increased psychomotor activity in response to the dopamine agonists amphetamine and apomorphine [44-46], decreased efficacy in models of antipsychotic-like effects $[9,10]$, and increased pursuit of reward cues in response to amphetamine [11-13]. Many of the older animal studies showing that chronic antipsychotic treatment produces dopamine $\mathrm{D}_{2}$ receptor upregulation have used very high doses of antipsychotic/ $\mathrm{D}_{2}$ receptor occupancy. However, recent studies show that antipsychotic treatment regimens that produce clinically relevant levels of $\mathrm{D}_{2}$ occupancy can also increase $\mathrm{D}_{2}$ density. For instance, in rats, chronic treatment with haloperidol using doses that achieve $69-82 \% \mathrm{D}_{2}$ occupancy $( \pm 0.64-2.7 \mathrm{SEM}$; as measured on day 13 of ongoing treatment) significantly increases $\mathrm{D}_{2}$ and $\mathrm{D}_{2}{ }^{\text {High }}$ receptor density in the striatum [9, 10]. It is also noteworthy that these levels of $\mathrm{D}_{2}$ occupancy by antipsychotics also increase the incidence of vacuous chewing movements in rats - an animal model of TD [47].

Data from animal studies show that chronic exposure to antipsychotic medications increases $\mathrm{D}_{2}$ receptor numbers most prominently in the caudate-putamen and the nucleus accumbens $[48,49]$. Antipsychotic-induced dopamine supersensitivity is also linked to increased levels of $\mathrm{D}_{2}$ High receptors in these same brain regions $[9,10,50]$. In contrast, there are no consistent changes in $\mathrm{D}_{2}$ receptor numbers in the substantia nigra [51]. There are also no consistent alterations in the density of $\mathrm{D}_{1}$, acetylcholine, or GABA receptors in the striatum $[52,53]$, or in the levels of dopamine transporters in cortical or subcortical areas $[54,55]$. In the striatum, $\mathrm{D}_{2}$ receptors are located on both pre-and postsynaptic sites. The assays used to measure the level of $\mathrm{D}_{2}$ receptors in antipsychotic-treated animals do not discriminate between both $[9,10,50]$. However, there is reason to suspect a change in postsynaptic dopamine signaling. First, imaging studies in patients with schizophrenia who have been chronically treated with antipsychotic medications suggest that postsynaptic

Supersensitivity Psychosis dopamine receptors in the striatum might be supersensitive [56]. Second, studies in laboratory animals show no significant changes in the function of presynaptic elements within the dopamine system. For instance, chronic treatment with haloperidol does not change the ability of presynaptic $\mathrm{D}_{2}$ receptors to regulate dopamine overflow [57]. Antipsychotic-treated animals that are behaviorally supersensitive to the indirect dopamine agonist amphetamine also show normal levels of amphetamineinduced increases in dopamine overflow in the striatum $[10,58]$. However, these animals do show enhanced amphetamine-induced gene regulation in the striatum, suggesting a change in the postsynaptic response to amphetamine $[11,12]$.

While some antipsychotics may not elevate the density of $\mathrm{D}_{2}$ receptors, they can raise the number of dopamine $\mathrm{D}_{2}{ }^{\text {High }}$ receptors [25]. The number of dopamine $\mathrm{D}_{2}{ }^{\text {High }}$ receptors is elevated in animals that have been treated with antipsychotic drugs on a long-term basis [26]. This elevation occurs also in animals that have been made behaviorally supersensitive to dopamine receptor stimulation by lesions in the brain, knockout mutations, isolation since birth, and other methods including various types of drug treatments [26]; in fact, there are no known exceptions to this relation between dopamine supersensitivity and $\mathrm{D}_{2}{ }^{\text {High }}$ elevation. All antipsychotics, including the most recent SGAs, can increase the number of $\mathrm{D}_{2}{ }^{\text {High }}$ receptors in the brain striata of animals $[25,26$, 59-62]. It is important to note that the number of $\mathrm{D}_{2}$ receptors themselves may or may not be elevated, but the level of $\mathrm{D}_{2}$ High receptors is elevated, indicating a change in the biological control of the state of convergence from the low- to the high-affinity state, and back to the lowaffinity state. This could involve alterations in the guanine-nucleotide system controlling the balance between $\mathrm{D}_{2}{ }^{\text {High }}$ and $\mathrm{D}_{2}{ }^{\text {Low. }}$. For example, the intracellular level of guanosine triphosphate is normally about $10 \mu \mathrm{mol} / \mathrm{L}$ [26], but this may be altered in the supersensitive state. Although this remains to be determined, a small reduction in guanosine triphosphate levels adjacent to the neuronal membranes may shift the balance toward an elevation in $\mathrm{D}_{2}{ }^{\text {High }}$. These observations suggest that when antipsychotic treatment is initiated, the medications act in a system with normal levels of $\mathrm{D}_{2}$ and $\mathrm{D}_{2}{ }^{\text {High }}$ receptors. In this context, the majority of $\mathrm{D}_{2}$ receptors are occupied by antipsychotics, and the balance is shifted towards reduced dopamine-mediated signaling. With long-term antipsychotic treatment, the $\mathrm{D}_{2}$ and $\mathrm{D}_{2}{ }^{\mathrm{High}}$ receptor numbers can increase, most prominently in the striatum. Now, the balance is shifted towards enhanced dopamine-

Psychother Psychosom 2017;86:189-219 191 
Fig. 1. Theoretical model illustrating the ability of chronic treatment with antipsychotic medication to induce dopamine supersensitivity. It is proposed that with chronic antipsychotic treatment (synapse on the right), there are increases in the numbers of dopamine $D_{2}$ receptors $\left(D_{2}\right)$ and $\mathrm{D}_{2}$ receptors in a high-affinity state for dopamine $\left(\mathrm{D}_{2}{ }^{\mathrm{High}}\right)$ in the striatum, without significant changes in presynaptic dopamine release, synthesis, or reuptake. In turn, the $\mathrm{D}_{2}$ receptor upregulation enhances $\mathrm{D}_{2}$-mediated dopamine signaling, shown by the red arrows, thus producing a state of supersensitivity to dopamine agonist stimulation. The functional consequences of this dopamine supersensitivity would include antipsychotic treatment failure, supersensitivity-related psychosis, and movement disorders (see text). DAT, dopamine transporter.

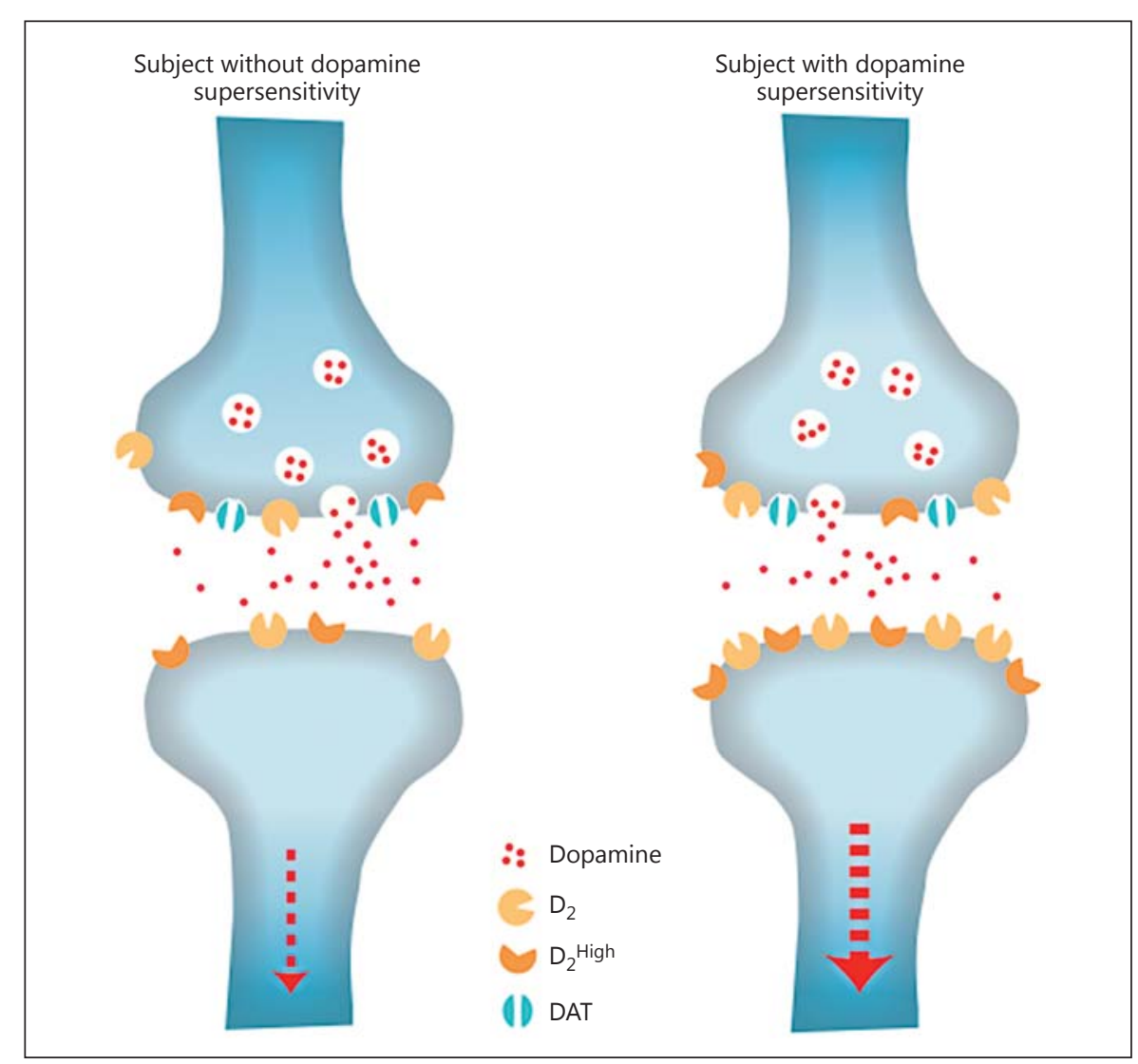

mediated signaling, at least in the striatum. This is likely mediated by postsynaptic processes and contributes to a supersensitive behavioral response to dopamine stimulation. This dopamine supersensitivity in turn can contribute to antipsychotic treatment tolerance, de novo psychotic symptoms, and movement disorders. Figure 1 illustrates this theoretical model, which is based primarily on behavioral and neuropharmacological data from studies in laboratory animals.

Many studies link the emergence of dopamine supersensitivity to an increase in the density of striatal $\mathrm{D}_{2}$ receptors, in particular $\mathrm{D}_{2}{ }^{\mathrm{High}}$ receptors, but the nature of this relationship is not yet clearly understood. The available evidence suggests that a change in the density of $\mathrm{D}_{2}$ and/or $\mathrm{D}_{2}{ }^{\text {High }}$ receptors might be necessary but not sufficient to invoke dopamine supersensitivity. For instance, in laboratory animals, increases in $\mathrm{D}_{2}$ receptors and $\mathrm{D}_{2}{ }^{\text {High }}$ receptors can be seen at time points during ongoing antipsychotic treatment when there is no behavioral evidence of dopamine supersensitivity [10] and also following antipsychotic treatment regimens that do not induce dopamine supersensitivity [9]. A study imaging a small number of drug-naïve $(n=10)$ and drug-free patients $(n=3)$ with schizophrenia spectrum disorders found no evidence of elevated levels of $\mathrm{D}_{2}{ }^{\text {High }}$ receptors, as labelled using $\left[{ }^{11} \mathrm{C}\right]-(+)-\mathrm{PHNO}\left(\left[{ }^{11} \mathrm{C}\right]-(+)-4\right.$-propyl9-hydroxynaphthoxazine) as a positron emission tomography (PET) radiotracer [63]. However, $\left[{ }^{11} \mathrm{C}\right] \mathrm{PHNO}$ is not considered to be selective in vivo for $\mathrm{D}_{2}{ }^{\text {High }}$ receptors, since it measures both $\mathrm{D}_{2}{ }^{\mathrm{High}}$ and $\mathrm{D}_{2}{ }^{\text {Low }}$ receptors, and it also binds to $\mathrm{D}_{3}$ receptors [64]. As the authors wrote in their abstract [63], there is also the possibility that "receptors with high affinity are not accessible by $\left[{ }^{11} \mathrm{C}\right] \mathrm{PHNO}$ because they are occupied by endogenous dopamine." The patient selection in this study [63] must also be considered since it represents a rare group of psychotic patients with relatively low scores for positive symptoms (mean 20.9, SD 7.14) during a drug-free period (2 weeks for oral and 2 years for depot intramuscular antipsychotics, mean length of drug treatment: 4 months).

$\mathrm{D}_{2}$ agonists, such as dopamine, reduce $\mathrm{D}_{2}$ density [65] and produce internalization of $\mathrm{D}_{2}$ receptors [65]. In contrast, antipsychotics reduce internalization of $\mathrm{D}_{2}$ receptors and produce an increase in brain $\mathrm{D}_{2}$ receptor mRNA, 
a determinant of $\mathrm{D}_{2}$ receptor density [66]. $\mathrm{D}_{2}$ upregulation persists after discontinuation of antipsychotics [44] and produces alterations in intracellular systems, including $G$ protein-coupled receptor kinase-6 (GRK-6) and $\beta$-arrestin 2 , both of which are important for the internalization of $\mathrm{D}_{2}$ receptors. In rats chronically treated with haloperidol, Oda et al. [67] showed that the increase in the locomotor response to the indirect dopamine agonist methamphetamine was associated with a higher ratio of striatal GRK6 to $\beta$-arrestin 2. Oda et al. [68] also reviewed the mechanisms underlying antipsychotic-induced increases in $\mathrm{D}_{2}$ receptor density and concluded that, because of its role in dopamine-mediated signaling, glycogen synthase kinase-3 (GSK-3) could be associated with the compensatory increase in $\mathrm{D}_{2}$ receptor density and the activation of the $\beta$-arrestin 2/AKT/GSK-3 signaling pathway. However, dopamine D3-knockout mice do not exhibit dopamine supersensitivity [26], and GSK-3 $\beta$ knockout mice have only minor changes in the function of $\mathrm{D}_{2}$ receptors as measured by the density of $\mathrm{D}_{2}{ }^{\text {High }}$ states [26]. These findings question the role of GSK-3 in the compensatory increase in $\mathrm{D}_{2}$ density following antipsychotic treatment.

\section{Clinical Characteristics and Consequences of SP in the Era of SGAs}

In order to develop SP, patients must have received antipsychotics for at least 3 months of cumulative exposure $[14,69]$, which is the time period necessary for an antipsychotic drug to persistently increase $\mathrm{D}_{2}$ receptor density. This estimated time period comes from clinical data on patients with TD accumulated before 1982 (following the New Clinical Drug Evaluation Unit [NIMH] Tardive Dyskinesia Workshop, which included TD research experts [1981]), which led to the 3-month criterion of cumulative antipsychotic exposure chosen for the research diagnostic criteria of TD by Schooler and Kane [70]. This criterion has been used since then for all clinical and research data in TD. A diagnosis of SP cannot be made in patients with severe psychosis that have not previously responded to antipsychotic treatment $[4,37,71]$. Online supplementary Table 1 (for all online suppl. material, see www.karger. com/doi/10.1159/000477313) summarizes the diagnostic criteria first proposed for SP [14]. These criteria were derived from outpatients chronically treated with long-acting (LA) injectable and oral FGAs $[14,28,30]$, including 267 outpatients treated primarily with fluphenazine $[69,72]$. The concept of SP was based

Supersensitivity Psychosis on psychosis with characteristics similar to TD $[1,14]$ : it becomes manifest or overt during drug discontinuation/ dose reduction, and it occurs after long-term treatment, can be reversible as a withdrawal rebound psychosis, and masked by the causing drug during many years $[28,30]$. SP relapses consist of rapid onset of positive psychotic symptoms, including illusions, hallucinations, loss of attentional focus, Schneider passivity experiences, and delusions $[73,74]$, which can be more severe or not previously seen. Psychotic symptoms in patients with SP are worsened by life stress [14], minor life events, or daily hassles [37, 38], all of which can unmask both SP and TD $[1,14]$.

Antipsychotic administration increases the availability of $\mathrm{D}_{2}$ receptors, and this is linked to hyperdopaminergic behaviors in animals, and TD and SP in patients $[1,4]$. It is possible that excessive dopamine-mediated signals via $\mathrm{D}_{2}$ receptors promote rapid psychotic relapses in SP patients after drug discontinuation/dose reduction/ switch of antipsychotics. These acute psychotic symptoms are improved at least initially by increasing antipsychotic dose [14, 30]. While dose increases temporarily mask both motor abnormalities and SP [1], when dose is later reduced, this worsens supersensitivity symptoms, perhaps by unblocking the upregulated $\mathrm{D}_{2}$ receptors, which produces an increase in dopamine signals, leading to exacerbation of psychosis and dyskinesia [1]. During antipsychotic treatment, there might be an optimal range of $\mathrm{D}_{2}$ receptor occupancy by antipsychotic treatment. This optimal range is determined by patient-specific changes in $\mathrm{D}_{2}$ receptor density, and it might prevent further compensatory up- or downregulation of these receptors [4].

Recent studies in the era of SGAs have investigated the prevalence of SP. We will review 3 studies [34-36], 2 specifically focusing on TR schizophrenia (online suppl. Table 2). We will then review 2 studies $[37,38]$ investigating $\mathrm{SP}$ as a potential cause of relapse in schizophrenia. All studies used criteria derived from Chouinard [14] work published in 1991.

\section{SP Studies in TR Schizophrenia}

Suzuki et al. [35] examined SP in 147 schizophrenic patients who met Juarez-Reyes criteria for treatment resistance $[75,76]$. The characteristics of these patients are given in online supplementary Table 2. Patients were identified as having SP if they met at least one of Chouinard's [14] criteria: rebound psychosis, tolerance to antipsychotic therapeutic effects, or TD. The authors [35] reviewed all inpatient and outpatient medical re-

Psychother Psychosom 2017;86:189-219 
cords from 3 psychiatric hospitals, and 611 patients with a diagnosis of schizophrenia were identified, 202 (33\%) met Juarez-Reyes criteria [75, 76], and 147 were included. It should be noted that there were no patients taking clozapine given that it was not approved yet in Japan when the study was initiated. There were significantly more patients with Carpenter deficit schizophrenia [77] without SP than with SP. This finding is consistent with prior studies showing that SP is more prevalent in good prognosis schizophrenia [72]. Scores on the Brief Psychiatric Rating Scale (BPRS) [78] were not significantly different between patients with and without SP [78]. The authors found a prevalence of $72 \%(106 / 147)$ for at least 1 SP episode in TR patients on SGAs (olanzapine, paliperidone, perospirone, quetiapine, and risperidone) (online suppl. Table 2). TR patients with SP had significantly more drug-induced movement disorders including parkinsonism [79] than patients without SP.

In the second study of SP by Kimura et al. [34], LA injectable risperidone was given as adjunctive therapy to TR schizophrenia in a 1-year multicenter prospective followup study $(n=115)$. Patients were diagnosed as having SP if they met at least one of Chouinard's [14] criteria: withdrawal psychosis, tolerance to antipsychotic effects, new psychotic symptoms, or symptoms of greater severity upon drug discontinuation/dose reduction, and a history or presence or TD. Patient characteristics are given in online supplementary Table 2 . The mean duration of illness was 20 years, the mean dose was equivalent to $1,000 \mathrm{mg}$ chlorpromazine/day [80], and oral risperidone, olanzapine, and quetiapine were the antipsychotics most often taken concomitantly with LA injectable risperidone (online suppl. Table 2). The prevalence of SP in TR schizophrenia was 65\% (61/94) [34]. At baseline, schizophrenia patients with SP had higher total scores for drug-induced movement disorders on the Extrapyramidal Symptom Rating Scale (ESRS) [81, 82] and higher scores on the negative symptoms subscale of the BPRS [83]. Both SP and non-SP groups improved with adjunctive LA injectable risperidone, but the SP group showed significantly greater improvement in the BPRS total score and had a greater number of drug responders [34] (online suppl. Table 2). Kimura et al. [84] did a second-year follow-up in patients $(n=75)$ who completed the first year, and added 14 schizophrenic patients meeting the same inclusion criteria for treatment resistance $[75,76]$. Similar results were found in both cohorts. Patients with SP showed greater improvement in BPRS total scores, positive and negative symptom subscores, and significantly less relapses during the first- and second-year follow-up than TR patients without SP.

The studies by Kimura et al. [34] and Suzuki et al. [35] highlight the clinical characteristics of SP patients in the era of SGAs: high prevalence $(70 \%)$ of drug resistance, increased risk for drug-induced movement disorders, use of high chlorpromazine-equivalent doses, and a better clinical response in patients with SP than patients without SP (online suppl. Table 2). A better drug response in patients with SP was also previously reported in patients treated with FGAs $[69,72]$. The significant improvement in BPRS negative symptoms probably includes negative symptoms secondary to positive symptoms [1]. The studies of Kimura et al. [34, 84] also confirm that TR patients with SP are better drug responders than patients without SP $[14,72]$.

\section{SP during the Switch to Aripiprazole}

Takase et al. [36] examined clinical characteristics of SP patients in a retrospective study of 264 schizophrenic patients who had their antipsychotic treatment gradually switched to aripiprazole. All in- and outpatient medical charts of the Chiba University Hospital (Japan) were reviewed for a diagnosis of schizophrenia from September 2006 to December 2012. Patient characteristics are given in online supplementary Table 2. Patients were identified as having SP if they met at least one of Chouinard's [14] criteria: withdrawal psychosis, tolerance to antipsychotic effects, or mixed, meeting the 2 previous criteria and having new psychotic symptoms or psychotic symptoms of greater severity upon antipsychotic discontinuation/dose reduction/switch of antipsychotics. The prevalence rate of SP was found to be $26.5 \%$ (70/264) [36]. Drug-induced movement disorders and minor life events were not considered in this study. The authors found that significantly $(p<0.01)$ more patients with SP $(23 \%, 16 / 70)$ had worsening of their positive symptoms compared to non-SP patients $(8 \%, 16 / 194)$, and that significantly less patients with SP $(20 \%, 14 / 70)$ were able to continue aripiprazole compared to non-SP patients $(52 \%, 100 / 194)$. At initiation of aripiprazole, SP patients were taking significantly higher doses of SGAs (equivalent to $762.4 \pm 376.0 \mathrm{mg}$ chlorpromazine/day, mean \pm SD) compared to patients without SP $(473.5 \pm 373.3 \mathrm{mg} /$ day $)$. Nearly all patients in both groups were on SGAs, and only 7.1\% (5/70) of SP patients were taking FGAs compared to $10.3 \%(20 / 194)$ in the non-SP group (online suppl. Table 2). Psychotic worsening occurred 19 weeks after aripiprazole initiation, at the dose of $20 \mathrm{mg} /$ day and after a $45 \%$ reduction of prior antipsychotics. It should be noted that non-SP 
patients treated with high antipsychotic doses (mean dose equivalent to $662.7 \pm 294.9 \mathrm{mg}$ chlorpromazine/day) also had a worsening of their positive psychotic symptoms by aripiprazole, suggesting that aripiprazole could unmask covert SP.

\section{Studies of SP as a Cause of Relapse in Schizophrenic}

Patients without Antipsychotic Discontinuation/Dose Reduction/Switch

In 2 clinical studies of psychotic relapse, Fallon and Dursun [37] and Fallon et al. [38] examined the link between SP and relapse in treatment-adherent schizophrenic patients without drug discontinuation/dose reduction/ switch of antipsychotics. Patients taking clozapine or quetiapine were excluded because of the particular $\mathrm{D}_{2}$ pharmacology of these drugs compared to other antipsychotics (see Rebound Psychosis section) and the different types of relapses associated with them $[1,33]$. In the first study [37], 128 schizophrenic patients who had a recent psychotic relapse were identified in a catchment area of 220,000 (NHS); 48/128 (37.5\%) met the inclusion criteria; $22 / 48(45.8 \%)$ patients completed the study protocol, including the Present State Examination (PSE-10) [85]. Seven $(31.8 \%)$ of the 22 patients had TD using a specific TD scale [86]. Fallon and Dursun [37] defined SP using the Chouinard [14] criteria and used the presence of TD to identify relapsing patients with SP. Patients who were relapsing and who also had TD were on higher antipsychotic doses, had more positive psychotic symptoms, a longer duration of illness, more minor life events, and were older.

In the second study, Fallon et al. [38] identified 41 treatment-adherent schizophrenic patients with a recent relapse not associated with antipsychotic discontinuation/dose reduction/switch of antipsychotics. Patients were recruited through their consultant psychiatrist and assessed with the Life Events and Difficulty Schedule (LEDS) [87], the PSE-10 [85], and the Abnormal Involuntary Movement Scale (AIMS) [86]. The authors found that $39 \%(16 / 41)$ of relapsing patients with TD received higher doses of antipsychotics, had less therapeutic response, more residual symptoms, and more minor life events, and met criteria for SP. Of the 41 patients, $54 \%$ (22) were taking oral SGAs and $12 \%(5 / 41)$ were on depot SGAs, while $81 \%(13 / 16)$ of SP relapsing patients were on SGAs. The majority of patients on mood stabilizers $(66.6 \% ; 10 / 15)$ did not have SP. This is noteworthy since antiseizure drugs have been found to have beneficial effects on SP patients [69].

Supersensitivity Psychosis
Fallon et al. [38] found that SP was potentially linked to relapse in $30-40 \%$ of patients who experienced relapse without drug discontinuation/dose reduction/switch. They replicated the results of their first study. This prevalence rate for SP is similar to rates found in other studies of patients treated with SGAs [34-36] and FGAs [1, 72]. As expected from previous studies [14], SP patients relapsing without drug discontinuation/dose reduction/ switch of antipsychotics have a severe form of drug-induced psychosis: poor drug response, high chlorpromazine equivalent doses, and more residual negative symptoms. In addition, Fallon et al. [38] showed a significant relationship between minor life events and relapse [88] in patients with both TD and SP.

\section{Evolving Conceptual Framework of Antipsychotic-Induced Dopamine SP in Line with Other CNS Drug Withdrawal Syndromes}

Classification of Antipsychotic Withdrawal Syndromes

Based on ongoing research into SP characteristics, along with evidence for withdrawal symptoms found with other CNS drug classes, we present a conceptual framework [1,41] for identifying SP and other antipsychotic withdrawal syndromes (Tables 1, 2). Chouinard and colleagues $[1,31,89,90]$ reported 3 types of withdrawal syndromes associated with CNS drugs, including opiates, barbiturates, and alcohol: (1) new or classical withdrawal symptoms; (2) rebound; and (3) postwithdrawal disorders (Table 1). These 3 types of withdrawal syndromes need to be differentiated from relapse and recurrence of the original illness. Relapse is defined as the gradual return to symptoms seen before treatment and entails a return of the ongoing episode, while recurrence is defined as a new episode of the illness (Table 1).

New and rebound symptoms occur up to 6 weeks after drug discontinuation/dose reduction/switch, depending on the drug terminal plasma half-life $\left(t_{1 / 2}\right)$. New and rebound symptoms of CNS drugs have been reported to be more frequent and severe with short $\mathrm{t}_{1 / 2}$ and high-potency drugs [1, 31, 89, 90]. New and rebound withdrawal symptoms are usually of short duration, persisting for a few hours to 2 weeks with complete recovery. However, if symptoms persist for more than 6 weeks, they become part of postwithdrawal disorders [41].

Fava et al. [91] proposed to replace the term discontinuation syndrome often used for selective serotonin reuptake inhibitors (SSRIs)/selective noradrenaline reuptake inhibitors (SNRIs) [92] and antipsychotic medica-

Psychother Psychosom 2017;86:189-219 
Table 1. Type of antipsychotic withdrawal compared to relapse and recurrence [41]

\begin{tabular}{|c|c|c|c|}
\hline Type/class & Peak onset/duration & Outcome & Symptoms \\
\hline New symptom & $\begin{array}{l}\text { Peak onset: } 36-96 \mathrm{~h} \text { after drug } \\
\text { discontinuation/dose reduction/switch, } \\
\text { may occur later depending on the duration of } \\
\text { action of the drug } \\
\text { Duration: lasts up to } 6 \text { weeks depending on } \\
\text { drug elimination } \\
\text { May last more than } 6 \text { weeks and } \\
\text { becomes postwithdrawal disorder }\end{array}$ & Reversible & $\begin{array}{l}\text { New withdrawal common to CNS drugs: } \\
\text { nausea, headache, sleep disturbance, anxiety, } \\
\text { decreased concentration, agitation, dysphoria, } \\
\text { aggression } \\
\text { Serotonergic withdrawal syndrome: } \\
\text { flu-like symptoms, diarrhea, disorientation, } \\
\text { coma, hyperreflexia, clonus } \\
\text { Muscarinic withdrawal syndrome: } \\
\text { nausea, vomiting, abdominal cramp, } \\
\text { hypothermia, sialorrhea, tremor, } \\
\text { parkinsonism, restlessness, insomnia } \\
\text { Adrenergic withdrawal syndrome: } \\
\text { headache, palpitation, tremor, increase in } \\
\text { blood pressure, increase in heart rate, } \\
\text { increased risk of myocardial infarction, anxiety } \\
\text { Histaminic withdrawal syndrome: } \\
\text { insomnia, increased seizure risk }\end{array}$ \\
\hline Rebound & $\begin{array}{l}\text { Peak onset: } 36-96 \mathrm{~h} \text { after drug } \\
\text { discontinuation/reduction/switch, or longer } \\
\text { depending on the duration of action of the } \\
\text { drug } \\
\text { Lasts up to } 6 \text { weeks depending on drug } \\
\text { elimination } \\
\text { May last more than } 6 \text { weeks and becomes } \\
\text { postwithdrawal disorder }\end{array}$ & Reversible & $\begin{array}{l}\text { Rebound psychosis: positive symptoms above } \\
\text { pretreatment levels: illusions, hallucinations, } \\
\text { delusions, catatonia, Schneider passivity expe- } \\
\text { riences }\end{array}$ \\
\hline $\begin{array}{l}\text { Persistent } \\
\text { postwithdrawal } \\
\text { disorders }\end{array}$ & $\begin{array}{l}\text { Peak onset: } 24 \text { h to } 6 \text { weeks after } \\
\text { drug discontinuation/dose reduction/switch } \\
\text { May last several months }\end{array}$ & $\begin{array}{l}\text { Persistent, but } \\
\text { remains } \\
\text { reversible }\end{array}$ & $\begin{array}{l}\text { 1. Return of psychotic symptoms above } \\
\text { pretreatment levels } \\
\text { 2. Emerging new psychotic symptoms of } \\
\text { another type, such as disorganized behavior }\end{array}$ \\
\hline Relapse & Onset: $24 \mathrm{~h}$ to 6 weeks & $\begin{array}{l}\text { Partial/complete } \\
\text { remission }\end{array}$ & $\begin{array}{l}\text { Return of ongoing episode, symptoms known } \\
\text { to the patient }\end{array}$ \\
\hline Recurrence & Onset: 6 months or more & $\begin{array}{l}\text { Partial/complete } \\
\text { remission }\end{array}$ & $\begin{array}{l}\text { New episode, symptoms known to the } \\
\text { patient }\end{array}$ \\
\hline
\end{tabular}

tions [93] by "withdrawal." CNS withdrawal occurs when the pharmacological effects of a drug diminish during medication discontinuation/dose reduction/switch, or in-between doses, which indicates an underlying pharmacological mechanism. The term discontinuation refers to the medical act of drug discontinuation or patient selfdiscontinuation. Furthermore, the term discontinuation is misleading since withdrawal symptoms may also occur with dose reduction or in-between doses for rapid-onset short-acting drugs. Examples include alprazolam and lorazepam, which can induce clock watching in-between doses, and clozapine which can induce late afternoon psychosis when given as a single dose at bedtime [41]. We will give criteria for each of the 3 types of withdrawal associated with antipsychotics $[1,41,94]$.

\section{New Symptoms}

New symptoms are the classic symptoms of withdrawal. They are not part of the patient's illness. New symptoms can be minor (anxiety, insomnia, and tremor) or major (seizures, psychosis, and death) [95]. Some are common to all CNS drugs, including narcotics, barbiturates, and alcohol, but each class of CNS drugs has its own specific new symptoms $[1,41,90]$. New symptoms common to CNS drugs include: nausea, headache, tremor, sleep disturbances, decreased concentration, anxiety, ir-
Chouinard/Samaha/Chouinard/Peretti/ Kanahara/Takase/Iyo 
Table 2. Diagnostic criteria for new symptoms induced by antipsychotic treatment

A. New symptoms occur after discontinuation/reduction/switch of antipsychotics

B. One (or more) of the following new symptom(s) common to CNS drugs: nausea, headache, tremor, insomnia, inattention, anxiety, irritability, agitation, aggression, depression, or dysphoria

C. Two (or more) of the following receptor-specific new symptoms in 2 (or more) different domains (general, cardiovascular, gastrointestinal, neuromuscular, sensory, cognitive, or autonomic/sex):

Serotonin withdrawal syndrome:

1. Flu-like symptoms, sweating, or chills (general)

2. Dizziness, light-headedness, or tachycardia (cardiovascular)

3. Diarrhea, loose stools, or abdominal pain (gastrointestinal)

4. Restlessness, myalgia, rigidity, hyperreflexia ${ }^{1}$, or inducible clonus ${ }^{1}$ (neuromuscular)

5. Paresthesia, electric shock sensations, or zaps (sensory)

6. Confusion, disorientation, amnesia, or coma (cognitive)

7. Premature ejaculation or genital hypersensitivity (autonomic/sex)

Muscarinic cholinergic withdrawal syndrome:

1. Agitation, insomnia, anxiety, or depression (general)

2. Dizziness, light-headedness, or tachycardia (cardiovascular)

3. Nausea, vomiting, salivation, diarrhea, loose stools, or abdominal cramp (gastrointestinal)

4. Tremor, parkinsonism, restlessness, myalgia, rigidity, or myosis (neuromuscular)

5. Paresthesia (sensory)

6. Confusion or disorientation (cognitive)

7. Hypothermia, sweating, or diaphoresis (autonomic)

Adrenergic withdrawal syndrome:

1. Headache, anxiety, or agitation (general)

2. Increased blood pressure, increased heart rate, risk of myocardial infarction ${ }^{1}$, angina pectoris, palpitation, or chest pain (cardiovascular)

3. Presyncope or tremulousness (neuromuscular)

4. Sweating (autonomic)

Histaminic withdrawal syndrome

1. Irritability, depressed affect, insomnia, or agitation (general)

2. Loss of appetite or nausea (gastrointestinal)

3. Tremulousness, incoordination, or increased inducible seizure ${ }^{1}$ (neuromuscular)

4. Lethargy or amnesia (cognitive)

D. Symptoms in criteria B and C are associated with a peak onset 36-96 h after drug discontinuation/reduction/switch of antipsychotics (or later depending on terminal plasma half-life)

E. Symptoms in criteria B and C are reversible and may last for up to 6 weeks after the peak onset (depending on terminal plasma half-life)

F. Symptoms in criteria B and C cause clinically significant distress or impairment in social, occupational, or other important areas of functioning

G. Symptoms are not due to a general medical condition and are not better accounted for by another mental disorder or substance use

${ }^{1}$ May last more than 6 weeks.

ritability, agitation, aggression, depression, or dysphoria [41], as listed in Tables 3 and 4. On the other hand, new drug-specific symptoms are linked to receptor binding affinities, and result from receptor supersensitivity which leads to increased neurotransmission due to removal of receptor blockade by antipsychotic treatment when medication is discontinued or switched, or dose is reduced [ 1 ,
41, 90]. New and rebound symptoms occurring during withdrawal and switch from and to SGAs (aripiprazole, asenapine, iloperidone, lurasidone, olanzapine, paliperidone, quetiapine, risperidone, sertindole, ziprasidone, and amisulpride) were reviewed recently by Cerovecki et al. [94]. In Tables 1 and 2, we integrate some of their findings on treatment-emergent symptoms related to 
removal of blockade or stimulation of dopamine and other receptors (serotonin, muscarinic, adrenergic, and histaminic receptors) by SGAs [94], and divide new antipsychotic-specific symptoms into: (1) serotonin withdrawal syndrome (equivalent to serotonin syndrome): flu-like symptoms, diarrhea, disorientation, coma, hyperreflexia, and stimulus-inducible clonus; (2) muscarinic withdrawal syndrome (also called cholinergic rebound syndrome): nausea, vomiting, abdominal cramps, hypothermia, increased salivation, tremor, parkinsonism, restlessness, and insomnia; (3) adrenergic withdrawal syndrome: increased blood pressure, headache, anxiety, agitation, increased heart rate, myocardial infarction, angina pectoris, palpitation, chest pain, presyncope, tremulousness, sweating, increased heart rate, myocardial infarction, hyperthermia, and fear; and (4) histaminic withdrawal syndrome: insomnia, agitation, tremulousness, increased seizure susceptibility, and amnesia (Table 2). Some new symptoms (Table 2) have been reported to occur more than 6 weeks after discontinuation: myocardial infarction and death after discontinuation of $\beta$-blockers [96]; hyperreflexia and inducible clonus after abrupt discontinuation of clozapine [97]; inducible seizure after discontinuation of chronic $\mathrm{H}_{1}$ antihistamine treatment in rodents [98], and persistent insomnia following drug discontinuation/dose reduction of central muscarinic anticholinergics [1,90], and alcohol [95].

\section{Rebound}

Rebound Syndromes Associated with CNS Drugs

The second type of CNS drug withdrawal consists of rebound symptoms (Tables 1,2) [41]. It refers to a sudden return of patient symptoms above pretreatment levels and is usually short lasting. Rebound symptoms should be distinguished from pharmacological rebound, which produces both new and rebound symptoms. Pharmacological rebound is caused by a sudden increase or decrease in receptor-mediated effects due to removal of receptor blockade following drug discontinuation/dose reduction. This includes adrenergic rebound [99], cholinergic rebound [100,101], serotonin rebound [97], and histamine rebound [98]. We make a distinction between new and rebound symptoms, though they may have the same pharmacological mechanism [1, 41, 94]. The difference between new and rebound symptoms is whether present before treatment and known to the patient (rebound) or not present before treatment (new) and known to the patient. Cholinergic rebound produces both new symptoms: nausea, vomiting, salivation, abdominal cramp, diarrhea, hypothermia, tremor, insomnia, depression, and
Table 3. Diagnostic criteria for rebound psychosis induced by antipsychotic treatment

A. Psychosis occurring after drug discontinuation/dose reduction/switch of antipsychotics, or in-between dose interval, after 3 (or more) months of cumulative exposure

B. Return of one (or more) pretreatment(s), known to patient, original positive symptom(s): illusion, hallucination, catatonia, Schneider passivity experience, and delusion, positive symptoms listed in the Rating Scale for Psychotic Symptoms (RSPS) $[73,74]$ :

1. Illusion (e.g., visual, auditory, olfactory, gustatory, cœnesthetic, tactile, or coincidence)

2. Hallucination (e.g., auditory, visual, olfactory, cœnesthetic, tactile, or kinesthetic)

3. Catatonia (e.g., motor catatonia, negativism, or thought blocking)

4. Passivity experience (e.g., thought insertion, movements or actions controlled by an external force, or speech controlled by an external force)

5. Delusion (e.g., love, wealth, fame, special gift or talent, special power, sex, being pregnant, being a parent or being married, reference of events or ideas about oneself, politics, religion or philosophy, occult, extraterrestrial, paranormal, misidentification, persecution, jealousy, hypochondriacal, or somatic)

C. Return of one (or more) positive symptom(s) of criterion $\mathrm{B}$, and two (or more) of the following criteria:

1. Severity above pretreatment levels

2. Rapid appearance

3. Rapidity after onset to reach peak of severity

4. Transient

5. Reversible

6. Psychological belief of the need for drug

7. Rapid improvement after reintroduction of the drug

D. Positive symptoms of criterion B are characterized by peak onset within 36-96 h after drug discontinuation/reduction/ switch or in-between doses for oral medications; for longacting (LA) injectable antipsychotics, peak onset occurs 1-7 days before receiving the next injection or end of injection dosing interval determined by terminal plasma half-life $\left(t_{1 / 2}\right)$ (see Lee et al. [153] for LA injection dosing intervals), e.g., LA injectable risperidone 1-7 days before receiving the biweekly injection, haloperidol decanoate or paliperidone palmitate 1- and 3-month formulations 1-7 days before receiving the 1- or 3-month injection $[14,30]$

E. Positive symptoms of criterion B last less than 6 weeks [28] after peak onset of symptoms of criterion D

F. Symptoms of criterion B cause distress or impairment in important areas of functioning

G. Symptoms of criterion B are not due to other mental disorders, medical conditions, or substance use
Chouinard/Samaha/Chouinard/Peretti/ Kanahara/Takase/Iyo 
Table 4. Diagnostic criteria for persistent postwithdrawal supersensitivity psychosis induced by antipsychotic treatment

A. Psychotic exacerbation or relapse occurring after drug discontinuation/dose reduction/switch, after 3 (or more) months of cumulative exposure to antipsychotics

B. Psychotic exacerbation or relapse associated with rapid appearance or reappearance of one (or more) positive symptom(s) upon antipsychotic discontinuation/dose reduction/switch: illusion, hallucination, loss of attentional focus (catatonia), Schneider passivity experience, and delusion, positive symptoms in the Rating Scale for Psychotic Symptoms (RSPS) [73, 74]:

1. Illusion (e.g., visual, auditory, olfactory, gustatory, cœenesthetic, tactile, kinesthetic, or coincidence)

2. Hallucination (e.g., verbal, musical, auditory other, visual simple, visual complex, olfactory, gustatory, cœnesthetic, tactile, kinesthetic, or vestibular)

3. Loss of attentional focus (e.g., motor catatonia, sensory negativism, or thought blocking)

4. Schneider passivity experience (e.g., thought insertion, movements, or actions or speech controlled by an external force)

5. Delusion (e.g., love, wealth, fame, special ability, gift or talent, special power, sex, being pregnant, a parent, or married, reference of events or ideas about oneself, politics, religion, or philosophy, occult, extraterrestrial, paranormal, misidentification, persecution, jealousy, hypochondriacal, or somatic)

C. One (or more) of the following major criteria

1. Rebound or withdrawal psychosis: rapid appearance of one (or more) positive symptom(s) of criterion B, known (rebound psychosis) or unknown to the patient, or new (withdrawal psychosis)

2. Rebound or withdrawal psychosis as defined in criterion $\mathrm{C} 1$ with emergence of one definite drug-induced movement disorder [31] including tardive dyskinesia (TD), or prior movement disorder; definite is defined as two Extrapyramidal Symptom Rating Scale (ESRS) [81, 82] items rated $\geq 2 / 6$ or one item $\geq 3 / 6$; no minor criterion needed

3. Severe rebound or withdrawal psychosis defined as one (or more) severe/extremely severe positive symptom(s) of criterion B, above pretreatment (rebound psychosis), or new psychotic symptoms, unknown to the patient (withdrawal psychosis) reflecting greater severity of illness, e.g., grossly disorganized behavior or loss of attentional focus (catatonia) criterion B; severe is defined as one RSPS [73, 74] item $\geq 5 / 6$; no minor criterion needed

4. Drug tolerance: relapse or exacerbation of positive symptoms that occurs due to lessening of drug therapeutic effects, with or without dosage reduction or switch of antipsychotics, and that cannot be controlled by an increase of $20 \%$ or more of the dose to achieve the same beneficial effects

5. Severe drug tolerance: relapse or exacerbation of positive symptoms that cannot be controlled or masked anymore by previously efficacious doses and doses equivalent to $\geq 600 \mathrm{mg}$ chlorpromazine/day/12 mg haloperidol/day; no minor criterion needed

6. Masked drug tolerance: presence of drug tolerance in the past as defined in criterion C4, but masked with doses equivalent to $\geq 600 \mathrm{mg}$ chlorpromazine/day/12 mg haloperidol/day

D. Minor criteria or risk factors: one is needed if only one major criterion other than C2, C3, or C5 is present:

1. History or presence of a definite drug-induced movement disorder of TD type, preferably using a standard scale for detection; definite is defined as two ESRS [81, 82] TD items rated $2 / 6$ or one TD item rated $\geq 3 / 6$ on the ESRS $[81,82]$

2. Patient needs doses equivalent to $\geq 600 \mathrm{mg}$ chlorpromazine/day/12 $\mathrm{mg}$ haloperidol/day with little therapeutic response

3. Clear exacerbation of psychosis by stress, minor life events, or daily hassles

4. Exacerbation of psychosis by dopamine partial agonist

5. Reappearance of one (or more) positive psychotic symptom(s) at the end of the injection dosing interval

6. Number of times an oral antipsychotic is given daily increased, or intramuscular interval is shortened to cover psychotic symptoms

7. Relapse occurs upon sudden decrease $(\geqq 10 \%)$ of medication but not if gradual

8. Greater frequency of psychotic relapse when continuously treated than when nonadherent to medication intake

9. High prolactin levels (1.5 higher than normal values) at least once when treated with antipsychotics

E. Psychotic exacerbations or relapses in criteria B and C are characterized by peak onset within $24 \mathrm{~h}$ to 6 weeks after drug discontinuation/dose reduction/switch for oral medications; for long-acting (LA) injectable antipsychotics, peak onset occurs 1-7 days before receiving the next injection or end of the injection dosing interval determined by terminal plasma half-life (see Lee et al. [153] for LA injection dosing intervals) e.g., LA injection risperidone 1-7 days before receiving the biweekly injection, haloperidol decanoate and paliperidone palmitate 1-and 3-month formulations 1-7 days before receiving the 1 - or 3 -month injection $[14,30]$

F. Positive symptoms in criteria B and C last more than 6 weeks [28] after peak onset in criterion $\mathrm{E}$

G. History or presence of at least one psychotic disorder: schizophrenia, schizoaffective, schizophrenia spectrum disorders, and other idiopathic psychotic disorders including affective disorders

H. Not in the acute phase of first-episode psychosis

I. Not in continuous severe psychosis unresponsive to antipsychotics

J. The disturbance in criterion C causes impairment in important areas of functioning

K. The disturbance is not due to other medical conditions, other mental disorders, or substance use 
rebound symptoms listed in Tables 1 and 2; adrenergic rebound produces increase or "overshoot" in blood pressure and in heart rate above pretreatment and is also associated with new symptoms such as insomnia and anxiety $[99,102]$. Rebound anxiety and insomnia, seen with short-acting benzodiazepines [1], are also associated with new symptoms [103]. Withdrawal insomnia [104] and rebound insomnia [105] were identified as separate entities in all-night EEG recording studies.

Recently, we reviewed CNS drug rebound syndromes [41]. Several CNS drug rebound syndromes have been reported to occur following drug discontinuation after short-term use: REM rebound with barbiturates and nonbenzodiazepine hypnotics [106, 107]; rebound myocardial angina and infarction with propranolol [108]; rebound insomnia [105], rebound anxiety [103], and rebound panic [109], with benzodiazepines with short and intermediate $\mathrm{t}_{1 / 2}$ (triazolam, lorazepam, and alprazolam); and rebound depression [1, 41].

Rebound depression has also been observed at a greater frequency with high-potency (paroxetine) and/or short-acting SSRIs and SNRIs [1, 41]. In 2 double-blind placebo studies, patients with major depression had their maintenance paroxetine, sertraline, or fluoxetine treatment interrupted with placebo substitution and treatment reinstitution [110, 111]. In one of the studies [110], patients taking paroxetine and sertraline had a sudden worsening of depressive symptoms upon drug discontinuation with a return to baseline depression measurements after reinstitution of the treatment. In both studies $[110,111]$, patients taking fluoxetine did not have rebound depression, confirming that fluoxetine with a long $t_{1 / 2}$ including norfluoxetine is less likely to cause rebound [41]. In contrast, patients treated with paroxetine had rebound depression in both studies [41, 110, 111].

The prevalence of high-dose use [112] is greater among patients taking benzodiazepines with short-intermediate $_{1 / 2}$ (e.g., triazolam, lorazepam, and alprazolam) than patients taking benzodiazepines (clonazepam, clobazam, and diazepam) with long $\mathrm{t}_{1 / 2}$; these differences persist even after 12-year long-term use [112]. Rebound syndromes respond rapidly to reinstitution of the offending drug, which often leads patients to false beliefs about efficacy and need for the drug [90]. The psychological belief of needing the drug for fear of having symptoms return appears the same for short-acting and short $t_{1 / 2}$ CNS drugs, including antipsychotics (quetiapine) [1], paroxetine (SSRI) [41], lorazepam [103], alprazolam [112], cocaine [113], and heroin [114]. Rapid-onset drugs with short $t_{1 / 2}$ will have an increased risk of rebound upon withdrawal, as illustrated by cocaine and heroin [114]. Rebound symptoms can be persistent in some patients, for example long-lasting insomnia after withdrawal from sustained alcohol abstinence [95] and rebound psychosis after long-term antipsychotic treatment $[1,14]$.

\section{Rebound Psychosis}

The proposed diagnostic criteria for rebound psychosis are given in Table 3. Rebound psychosis is defined by a rapid return above pretreatment levels of at least one positive symptom listed in the Rating Scale for Psychotic Symptoms (RSPS) $[73,74]$. Rebound psychosis lasts up to 6 weeks after peak onset (Table 1); if it persists longer, it becomes a postwithdrawal disorder, as for new symptoms persisting more than 6 weeks. Rebound psychosis is generally short lasting and considered as a reversible form of SP, equivalent to reversible withdrawal TD [1]. Any rebound symptom, such as an increase in blood pressure, myocardial infarction, insomnia, or psychosis, has the potential to become a persistent postwithdrawal disorder when lasting more than 6 weeks, often lasting several months and even years $[1,41,95,96]$.

As with other CNS drugs (benzodiazepine, SSRI/ SNRI, heroin, and cocaine), antipsychotics that are rapidly eliminated and/or that rapidly dissociate from the $\mathrm{D}_{2}$ receptor including clozapine (time to peak concentrations in plasma, $\mathrm{t}_{\max }: 3-4 \mathrm{~h} ; \mathrm{t}_{1 / 2}: 16 \mathrm{~h}$ [115]) and quetiapine [116] ( $\mathrm{t}_{\max }: 1-1.8 \mathrm{~h} ; \mathrm{t}_{1 / 2}: 7 \mathrm{~h}$ [115]) have greater risks of rebound when medication is reduced, switched [59], or discontinued [1, 33, 39, 40]. Patients on clozapine monotherapy taken as a single dose at bedtime report late afternoon return of symptoms [1]. For both the immediate-release formulation (IR) and the extended-release formulation (XR) of quetiapine, it is common in clinical practice to have difficulty in decreasing the drug dose, as it causes rebound anxiety and rebound insomnia (the drug possessing anxiolytic and hypnotic effects [117]), and later causes an in-between dose clock watching for return of symptoms, e.g., patient watches the clock to make sure the next dose is not missed for fear that symptoms might return, when given once a day above $150 \mathrm{mg}$ [117] over a 2 -month period $[1,41]$. The pharmacokinetics [118] and the central $\mathrm{D}_{2}$ receptor occupancy pharmacodynamics [119] of IR quetiapine given twice daily and XR quetiapine given once daily are similar $[118,119]$. Rebound psychosis with SGAs was first seen with clozapine [33] and then quetiapine monotherapy [39], but was later seen with all SGAs [34-36], with overt prevalence depending on drug $t_{1 / 2}$ and potency.
200

Psychother Psychosom 2017;86:189-219 DOI: $10.1159 / 000477313$
Chouinard/Samaha/Chouinard/Peretti/ Kanahara/Takase/Iyo 
Quetiapine and clozapine have a particular $\mathrm{D}_{2}$ pharmacological profile compared to other SGAs: loose binding displaced rapidly from the $\mathrm{D}_{2}$ receptor [120], fast dissociation from the $\mathrm{D}_{2}$ receptor [116], brief and weak action of clozapine on brain dopamine systems $[116,121]$, and high transient initial $\mathrm{D}_{2}$ occupancy by quetiapine with minimal occupancy at the end of the dose interval [122]. This $\mathrm{D}_{2}$ profile of clozapine and quetiapine leads to differences in SP manifestations [1]: elevated incidence of rebound psychosis with clozapine $[1,33,39,101]$, which is a reversible withdrawal subtype of SP [1], and severe drug tolerance with IR quetiapine given as antipsychotic monotherapy [39]. This might be explained by initially high $\mathrm{D}_{2}$ occupancy followed rapidly by low occupancy at the end of the dosing interval [122].

\section{Postwithdrawal Disorders}

Postwithdrawal Disorders of CNS Drugs

Postwithdrawal disorders have been described with all classes of CNS drugs [1, 41]. Early recognition of postwithdrawal disorders for a given class of drugs is facilitated by the presence of high-potency drugs combined with short $t_{1 / 2}[1,123,124]$. Due to the short duration of action, there is a rapid decrease in occupancy of receptors produced in greater number by potent blocking drugs, thus resulting in a greater number of receptors in their unblocked state $[1,108,123,124]$; this was the case for $\beta$-adrenergic blocking drugs. As early as 1975 , dose was highlighted as an additional factor for early recognition of postwithdrawal disorder; $160-320 \mathrm{mg}$ propranolol/ day would produce an adrenergic rebound unmasked rapidly by discontinuation, which led to an increase in cardiac contractibility, heart rate, myocardial ischemia, and rapid death, even after short-term use (6-12 weeks) [108]. Interestingly, in this first report of adrenergic rebound, major complications such as death were seen in patients who responded better to propranolol [108], which is also a characteristic of SP, most often seen in good antipsychotic drug responders [14, 72]. Following abrupt withdrawal (even gradual withdrawal) of $\beta$-adrenergic drugs after long-term use, it was relatively easy to demonstrate an overshoot adrenergic rebound with pretreatment symptoms reappearing suddenly - increase in blood pressure, heart rate, myocardial infarction, headache, and anxiety above pretreatment levels $[96,102]$. The early recognition of supersensitivity rebound with $\beta$-adrenergic drugs helped to identify its underlying receptor supersensitivity mechanism through catecholamine stimulation by isoprenaline (isoproterenol), a nonselective $\beta$-adrenergic receptor agonist in pa-

Supersensitivity Psychosis tients $[99,124,125]$, and later identify persistent postwithdrawal disorders consisting of an increased risk of myocardial infarction and mortality following their discontinuation [96]. Houston and Hodge [102], in their review of $\beta$-adrenergic blocker withdrawal syndromes, described 7 studies showing rebound and persistent withdrawal with $80 \mathrm{mg} /$ day propranolol and a study showing these withdrawal syndromes after only 7 days of propranolol use. Doses below $80 \mathrm{mg}$ propranolol/day appear safe to use in psychiatric clinical practice, but gradual dose reduction of low-dose propranolol is also recommended especially in patients at risks of myocardial infarction and essential hypertension.

Rebound anxiety and insomnia were also first demonstrated with short-acting and potent benzodiazepines [90, $103,105]$, and later as postwithdrawal disorders for alcohol [95] and benzodiazepines [104, 126]. Other known postwithdrawal disorders are major depression and dysphoria in cocaine $[113,114]$ and amphetamine withdrawal [114]. Within a drug class, specific drugs such as fluphenazine, perphenazine, quetiapine, clozapine, triazolam, and paroxetine permitted identification of new postwithdrawal disorders [1, 33, 39, 41, 109, 127].

For SSRIs and SNRIs, several postwithdrawal disorders after long-term use have been described; interestingly, these postwithdrawal disorders consist of disorders that can be treated successfully by SSRIs and SNRIs, such as obsessive-compulsive, panic, generalized anxiety, and gambling disorders $[1,41,109,127-129]$. All these postwithdrawal disorders have been shown to occur more frequently with paroxetine $[41,109,129,130]$. This suggests that paroxetine should not be used anymore.

For antipsychotics, two persistent postwithdrawal disorders, TD and SP, have been described [14, 28, 30, $31,131]$. When the symptoms last less than 6 weeks, they are considered as withdrawal dyskinesia and rebound, or withdrawal psychosis, respectively. When the symptoms last longer, they become postwithdrawal disorders, TD, or SP [1]. Discontinuation of short- and long-term $\beta$-blocker therapy can uncover long-lasting $\beta$-adrenergic supersensitivity $[96,99]$. Similarly, it has been known since the 1970s that long- and short-term dopamine receptor blockade by antipsychotics can both produce receptor supersensitivity [132]. The persistence of the dopamine supersensitivity syndrome depends on the duration of the preceding blockade [132] and on the specific antipsychotics used (fluphenazine, perphenazine, clozapine, and quetiapine) $[1,41]$. Similarly to $\beta$-adrenergic supersensitivity which may occur early and severely with $\beta$-blockers [108], TD can occur

Psychother Psychosom 2017;86:189-219 DOI: $10.1159 / 000477313$ 
after short-term use (1 month) of chlorpromazine (FGA) in a patient with schizophrenia [133], and in a nonpsychiatric patient after a 4-month treatment with a gastric preparation containing trifluoperazine (FGA) and an anticholinergic drug [134] in an irreversible and extremely severe form.

Supersensitivity Psychosis

The proposed diagnostic criteria [14] for SP as a CNS postwithdrawal disorder [41] are presented in Table 4. The criteria take into account results from the 3 recent studies in patients treated with SGAs $(n=505)$ reviewed above [34-36], which examine the clinical characteristics of SP, 2 specifically focusing on TR schizophrenia (online suppl. Table 2). In addition, we took into account the results from the 2 studies by Fallon and Dursun [37] and Fallon et al. [38], which examined the link between SP and relapse in treatment-adherent schizophrenic patients without drug discontinuation who were not taking clozapine or quetiapine $[37,38]$.

Exacerbation of psychosis by dopamine partial agonists was added as a risk factor (minor criterion) following the study by Takase et al. [36]. Vulnerability to minor life events was explicitly added to the minor criterion of exacerbation of psychosis by stress, following the results of Fallon and Dursun [37] and Fallon et al. [38]. Finally, the criteria define severe therapeutic drug tolerance more precisely as a nonresponse to doses equivalent to $\geq 600$ $\mathrm{mg}$ chlorpromazine/day/12 mg haloperidol/day, when the patient has previously responded to lower doses. In addition, compared to 1991 criteria, major criteria define positive symptoms specifically $[73,74]$. Major criteria C2, $\mathrm{C} 3$, or $\mathrm{C} 5$ do not need minor criteria as was shown by the SP criteria used in the 3 recent Japanese studies of SP $(n=505)$, which included both patients with and without TR schizophrenia (online suppl. Table 2) [34-36], and in the 2 relapse studies [37, 38].

Major criteria define rapid psychotic exacerbation or relapse upon drug discontinuation/dose reduction/ switch of antipsychotics, and drug tolerance which refers to the lessening of drug therapeutic effects with continued treatment and the need for increasing doses to achieve the same beneficial effect. Minor criteria are risk factors for SP (Table 4); they help to identify patients at risk for $\mathrm{SP}$ relapse. One minor criterion is needed if only one of the major criteria present is $\mathrm{C} 1, \mathrm{C} 2$, or C6 (Table 4).

We will now describe how SP criteria might be linked to an increase in $\mathrm{D}_{2} / \mathrm{D}_{2}{ }^{\mathrm{High}}$ receptor density.

\section{Pharmacological Link between a Compensatory Increase in $D_{2} / D_{2}{ }^{\text {High }}$ Receptor Density and SP}

All antipsychotics, including the most recent SGAs [26], have the potential to produce $\mathrm{D}_{2}$ upregulation. For instance, using laboratory animals, Tarazi et al. [135] reported upregulation of $\mathrm{D}_{2}$ receptors by olanzapine, risperidone, and quetiapine. Kusumi et al. [136] showed an increase in striatal $\mathrm{D}_{2}$ density following subchronic treatment with doses of chlorpromazine and perospirone (SGA) that produce therapeutic levels of striatal $\mathrm{D}_{2}$ receptor occupancy but not with low doses of chlorpromazine, risperidone, and olanzapine. While some antipsychotics may not elevate the density of $\mathrm{D}_{2}$ receptors, they can still raise the number of dopamine $\mathrm{D}_{2}{ }^{\text {High }}$ receptors [25].

The increase in the number of $\mathrm{D}_{2}$ and/or $\mathrm{D}_{2}{ }^{\text {High }}$ receptors enhances dopamine-mediated transmission [4] (Fig. 1). This may lead to more severe psychosis than seen in previous episodes during SP relapse or exacerbations, with new schizophrenic symptoms of greater severity such as disorganized behavior [14]. Patients with SP are more vulnerable to stress $[14,69]$, minor life events, and daily hassles [14, 37, 38, 69]. Stress increases dopamine levels in the brain [137]. In the presence of increased $\mathrm{D}_{2} /$ $\mathrm{D}_{2}{ }^{\text {High }}$ density, stress-induced dopamine in the extracellular space will produce greater $\mathrm{D}_{2}$-mediated signaling, leading to vulnerability to minor life events in patients with SP $[14,69]$ even without drug discontinuation/dose reduction $[37,38]$. SP patients without drug discontinuation/dose reduction could be considered as having an overt form of SP $[1,14]$. As dopamine binds to $\mathrm{D}_{2}$ receptors in competition with antipsychotic drugs, antipsychotics with less $\mathrm{D}_{2}$ receptor affinity allow more dopamine to bind to the receptors, and psychotic relapses due to SP will appear more rapidly.

Another feature of SP is the gradual tolerance to the therapeutic effect of antipsychotic medications, where previously efficacious doses can no longer adequately control psychotic symptoms. Continuous $\mathrm{D}_{2}$ occupancy by antipsychotics, within or above the threshold for prolactin and movement disorders (i.e., in the $72-78 \%$ range $[4,138])$, increases $\mathrm{D}_{2}$ density as a compensatory reaction to reduced dopamine-mediated signaling. As $\mathrm{D}_{2}$ density increases, the therapeutic level of $\mathrm{D}_{2}$ occupancy (65\%) [4, 138] becomes higher [4], and previously efficacious doses are insufficient to suppress or cover psychotic symptoms. In order to improve psychotic symptoms, at least temporarily, higher doses are required [20], and therapeutic drug tolerance further develops. This has also been shown in animal models of antipsychotic-like efficacy, where
Chouinard/Samaha/Chouinard/Peretti/

Kanahara/Takase/Iyo 
continuous blockade of $\mathrm{D}_{2}$ receptors by antipsychotics, at clinically representative levels, produces tolerance to ongoing treatment, and higher doses can temporarily restore efficacy $[9,10]$. The optimal range of $\mathrm{D}_{2}$ occupancy in drug-naïve schizophrenia has been established [138], and theoretically determines the optimal dose range for antipsychotic drugs [4]. Therefore, patients who previously responded well to antipsychotics, but now have become poor responder or have histories of maintenance treatment with doses equivalent or higher than $600 \mathrm{mg}$ chlorpromazine/day and $12 \mathrm{mg}$ haloperidol/day are at increased risk for SP. Poor response to 2 antipsychotics at doses equivalent to or higher than $600 \mathrm{mg}$ chlorpromazine/day is a criterion for TR schizophrenia $[75,76]$.

Following antipsychotic discontinuation or sudden dose reduction, psychotic relapse develops more rapidly in patients with SP than in those without [69]. As the antipsychotic drug is eliminated with its specific $t_{1 / 2}$, endogenous dopamine would now have access to a greater number of $\mathrm{D}_{2}$ and $\mathrm{D}_{2}{ }^{\text {High }}$ receptors (Fig. 1), explaining why psychotic symptoms appear more rapidly in SP patients during drug discontinuation/dose reduction/ switch of medication. However, the delay before the appearance of psychosis will also depend on the $t_{1 / 2}$ of each drug.

As optimal therapeutic $\mathrm{D}_{2}$ occupancy increases [4], increasing the antipsychotic dose would further mask TD [139] and SP [1], produce parkinsonism and negative symptoms, but also temporarily improve positive symptoms $[4,34]$. Some patients with severe SP who are also taking high doses of antipsychotics may exhibit all of these symptoms at the same time $[1,34,140]$. This mixed syndrome of drug-induced movement disorders and psychosis is temporally improved by giving the antipsychotic in divided doses [69]. Thus, SP may be masked, overt, or mixed [1], like TD [19]. The fact that SP can be overt during dose reduction, and masked by the causing drug during treatment $[14,28,30]$, explains the therapeutic tolerance observed when antipsychotics can no longer mask psychotic symptoms at previously efficacious doses, and further increases in doses are necessary to obtain similar therapeutic effects $[14,28,30]$. Tolerance needs to be identified early to avoid increasing doses. Once therapeutic tolerance is identified, instead of dose increases to cover SP, strategies that we propose here should be considered, primarily the use of low doses of antiseizure drugs [1], the use of the minimal therapeutic dose of antipsychotic, and regular but intermittent dosing.

Switching from one antipsychotic to another can potentially induce or uncover SP $[14,37,69,94]$. Switching

Supersensitivity Psychosis antipsychotics will allow SP to emerge in patients either with or without a past history of SP [36]. This suggests that a medication switch can unmask SP induced by previous antipsychotic treatment, particularly in patients taking doses equivalent to $\geq 600 \mathrm{mg}$ chlorpromazine/ day/12 mg haloperidol/day.

SP often occurs in the presence or history of drug-induced movement disorders, most often parkinsonism or TD [14, 28, 30, 37]. This is expected since parkinsonism and other drug-induced movements are the best predictors for TD $[1,71,81]$ and SP $[1,37,38]$. As striatal $\mathrm{D}_{2}$ occupancy by antipsychotics exceeds $65 \%$, a clinical response is likely to appear, hyperprolactinemia when $>72 \%$ and parkinsonism and movement disorders when $>78 \%$ [138]. The therapeutic window of $65-72 \% \mathrm{D}_{2}$ occupancy proposed by Kapur et al. [138] in their PET study of first-episode schizophrenia is relatively narrow and corresponds to doses $>0.5 \mathrm{mg}$ haloperidol/day [138]. Iyo et al. [4] suggested to extend the therapeutic window to $>78 \%$, i.e., when movement disorders appear, since movement disorders are easier to detect clinically and also because not all antipsychotics increase prolactin. Therefore, continuous $\mathrm{D}_{2}$ occupancy by antipsychotics above the narrow therapeutic window of $65-72 \%$ [138] or above the $72-78 \%$ threshold for prolactin/movement disorders may produce undetected parkinsonism and SP $[1,4,19$, 28]. As already mentioned, Kapur et al. [138] found that the threshold level of striatal $\mathrm{D}_{2}$ receptor occupancy for movement disorders is $>78 \%$ in first-episode schizophrenia. While catalepsy is seen in rats with doses that occupy $>80 \%[141,142]$, dopamine supersensitivity can be seen at doses that occupy $<80 \%$ [9-12]. Indeed, in animal models of dopamine supersensitivity, the doses we have studied occupy $73-74 \%$ of striatal $\mathrm{D}_{2}$ receptors [9-12].

\section{Guidelines for SP and TD Prevention}

\section{Prevention and Detection of Overblockade of $\mathrm{D}_{2}$ Receptors}

The first step (Table 5) is the early detection of mild drug-induced movement disorders of the parkinsonian type $[1,71]$, regardless of whether dopamine blockade is continuous [43], intermittent, or repetitive [42], or produced by SGAs or FGAs. Using the ESRS $[81,82]$ in a PET study of first-episode schizophrenia, Kapur et al. [138] found that movement disorders were seen only in patients with $\mathrm{D}_{2}$ occupancy $>78 \%$. This suggests that overblockade of $\mathrm{D}_{2}$ receptors can be detected clinically with a movement disorder examination. A specific examination

Psychother Psychosom 2017;86:189-219 
Table 5. Guidelines for the prevention of supersensitivity psychosis (SP) and tardive dyskinesia (TD)

Prevention and detection of overblockade of D2 receptors

1. The use of a standard examination procedure such as the Extrapyramidal Symptom Rating Scale (ESRS) [81, 82] for early detection of mild movement disorders including parkinsonism and late movement disorders as TD

2. Give maintenance dose of the antipsychotic lower than doses given in the acute treatment; if this is not possible, think about SP and switch to antipsychotic drugs that will improve SP symptoms and permit further dose reductions or avoid further increase; it might be easier to detect SP than TD, thus also preventing TD

3. Once the patient is sufficiently stable through a low dose, choose to decrease dosing interval administration: for oral medications start a Monday-to-Friday schedule once/day; if symptoms return, change antipsychotic; for long-acting injectable secondgeneration antipsychotics (SGAs), increase injection intervals by 1 week per 3-month period to double original dosing interval, then decrease dose

Choice of the antipsychotic

1. The use of antipsychotics at doses associated with less movement disorders [31]:

SGAs at doses associated with few or no movement disorders

First-generation antipsychotics (FGAs) which induced less movement disorders turned out to have other significant side effects: thioridazine, diphenylbutylpiperines (pimozide), and benzamides (sulpiride, amisulpride, or remoxipride); most of them have been removed for use in several countries (cisapride or remoxipride) or restricted (US boxed warning for TD and movement disorders) (metoclopramide), or never approved in the US and Canada (sulpiride and amisulpride); remoxipride was associated with aplastic anemia [218]; the main reason for withdrawal in several countries was QTc prolongation, proarrhythmia, torsades de pointes and increased mortality (thioridazine, pimozide, cisapride, sulpiride, and amisulpride) [219-221]; high prolactin is also well known for amisulpride [222] and was problematic for approval in several countries; both sulpiride and amisulpride were never approved in Canada and the US, because of issues regarding their toxicity; Leucht et al. [222, p. 960] wrote: "Despite the collaboration of its manufacturer, no useable data on amisulpride were available, but its high prolactin risk is well known... We emphasize that amisulpride was regarded as benign in some guidelines, but our findings show that it might not be a result that is consistent with an analysis of amisulpride overdoses"; metoclopramide and cisapride, the most prescribed benzamides, were withdrawn or given a black box warning - metoclopramide because of severe movement disorders including TD and cisapride because of cardiac toxicity

2. Avoiding the use of antipsychotics that increase the risk of SP

FGA with human cloned $\mathrm{D}_{2}$ binding affinities higher than that of haloperidol; fluphenazine and perphenazine [26] should be avoided

SGA with transient high $\mathrm{D}_{2}$ occupancy [122] and loose $\mathrm{D}_{2}$ receptor binding [120], quetiapine, should not be used longer than 2 months at doses $\geq 150 \mathrm{mg}$ /day; at doses $\leq 150 \mathrm{mg}$ /day we need to verify regularly the presence of rebound anxiety or insomnia

3. Use of dopamine partial agonists at low doses

Low-dose (<20 mg/day) dopamine partial agonists (aripiprazole) early in the treatment before SP develops, or, later, look for exacerbation of psychosis and relapse while initiating a dopamine partial agonist; use aripiprazole preferably with low-dose antiseizure drug (see next)

Use of an antiseizure drug at low doses

1. The use of low doses to initiate lamotrigine $2-25 \mathrm{mg} /$ day during the first week, with increases of $12.5 \mathrm{mg} / \mathrm{day}$ per week the following weeks, if necessary to reach $200 \mathrm{mg} /$ day, or use low-dose valproic acid (125-500 mg/day)

for movement disorders will also permit identification of emergent psychiatric symptoms caused by movement disorders [1]: akinesia producing depression and dysphoria [143-145], facial mask, blunted affect, rigidity, motor retardation [1,81], akathisia, agitation/anxiety/insomnia, and suicidal ideation $[146,147]$. It will permit early recognition of iatrogenic psychiatric symptoms confounded with movement disorders [1], akinesia confounded with psychomotor retardation, akathisia with agitation, and TD with mannerisms and schizophrenic abnormal movements $[1,81]$, symptoms which will often trigger dose increases and a consequent overblockade of $\mathrm{D}_{2}$ receptors. In the same PET study of first-episode schizophrenia, Ka- pur et al. [138] showed significant hyperprolactinemia at $>72 \%$ of $\mathrm{D}_{2}$ occupancy. Thus, when prolactin is increased by an antipsychotic, it can be used for early detection of $\mathrm{D}_{2}$ overblockade, which is consistent with our earlier findings with prolactin $[28,30]$ and antipsychotic plasma levels [19]. Furthermore, antipsychotic plasma levels in patients were measured by the same radioreceptor technique [19], using calf caudate membranes (technique from Bruce Cohen, Harvard University, MA, USA). Since prolactin, when elevated by antipsychotics, provided overall similar findings as antipsychotic plasma levels [19], patients with prolactin measurements appeared more practical for long-term follow-up [Chouinard and 
Jones: Clinical application of the neuroleptic radioreceptor assay in the management of schizophrenia 1982-85 Health and Welfare Canada, unpubl. study]. In addition, Kapur's findings [138] show that $\mathrm{D}_{2}$ occupancy levels linked to hyperprolactinemia $(72 \%)$ are close to levels linked to parkinsonism (78\%). Finally, the findings confirm the relevance to use of prolactin level measurements for early detection of $\mathrm{D}_{2}$ overblockade whenever appropriate, even for antipsychotics that raise prolactin levels inconsistently.

The second step (Table 5) is the administration of minimal therapeutic doses during maintenance treatment following the acute phase. The dose given in the acute phase is reduced gradually when initiating the maintenance treatment [148]. During the acute phase of psychosis, excessive dopamine release competes with antipsychotics for $\mathrm{D}_{2}$ receptor binding and depletes dopamine in the synaptic cleft [149], which creates a delay in reaching a new equilibrium.

The third step (Table 5) is to keep $\mathrm{D}_{2}$ occupancy within the optimal therapeutic range while maintaining the minimal therapeutic dose. This must take into account the side effects and patient's tolerability, which could be predicted by 4 pharmacokinetic parameters (clearance, volume of distribution, $\mathrm{t}_{1 / 2}$, and bioavailability) [150]. In clinical practice, one should take into account that peakto-trough plasma concentrations vary greatly and will depend on a number of variables. These include dosing interval and drug formulation [151], $\mathrm{D}_{2}$ receptor affinities, lipophilicity, active metabolites, patient characteristics (ethnicity and gender), concomitant medications, comorbid diseases, and general physical health $[151,152]$. While it is generally agreed that for oral SGAs (risperidone, olanzapine, clozapine, quetiapine, and ziprasidone) pharmacokinetic parameters are not sufficient for selection [115], selection of SGAs should be based on efficacy, side effects/tolerability, drug discontinuation-induced withdrawal symptoms and postwithdrawal disorders [1], and drug formulations $[4,151]$. For LA injectable antipsychotics, pharmacokinetic data in product monographs are of limited value for clinicians to choose the interval of administration [153]. In their recent review, Lee et al. [153] recommend using $t_{1 / 2}$ for LA injectable SGAs to decide on the dosing interval in clinical practice.

Continuous blockade of $\mathrm{D}_{2}$ receptors could contribute to the emergence of SP according to research conducted in animals. This work shows that when using the same achieved dose, peak level of $\mathrm{D}_{2}$ receptor occupancy, route, and duration of treatment, continuous antipsychotic treatment $/ \mathrm{D}_{2}$ receptor blockade (as achieved via subcuta-

Supersensitivity Psychosis neous osmotic minipump) favors dopamine supersensitivity, while intermittent treatment $/ \mathrm{D}_{2}$ receptor blockade (via daily subcutaneous injection) does not $[9,11,154]$. There are reports that intermittent antipsychotic administration via daily subcutaneous injection can produce dopamine supersensitivity [155-158]. However, the antipsychotic doses used are quite large and would produce excessively high and clinically unrepresentative levels of striatal $\mathrm{D}_{2}$ receptor blockade [159]. Continuous antipsychotic treatment could promote dopamine supersensitivity because it disrupts dopaminergic signaling unremittingly. This evokes compensatory changes including an increase in the number of striatal $\mathrm{D}_{2}$ and $\mathrm{D}_{2}{ }^{\text {High }}$ receptors in the striatum (Fig. 1) $[9,10,50]$. In contrast, intermittent antipsychotic treatment allows at least some level of dopaminergic signaling to occur in between peaks in $\mathrm{D}_{2}$ receptor occupancy. This might be sufficient to prevent the brain changes that produce dopamine supersensitivity.

The challenge is how to define "intermittent treatment" in clinical research and clinical practice. The clinician will often use short interdosing intervals (e.g., not taking antipsychotics on the weekends), to achieve minimal therapeutic dose [1]. In patients, there is likely a "break point" where if the antipsychotic dose/striatal $\mathrm{D}_{2}$ receptor occupancy has been low enough for long enough, the treatment might not be efficacious anymore to prevent relapses, thus being below the minimum therapeutic dosing. However, continuous dosing is not always necessary to maintain therapeutic efficacy. One prospective study by McCreadie et al. [160] indicates that intermittent administration with short interdosing intervals (as modeled in the animal studies described above $[9,11$, 154]) can be as effective as continuous dosing in preventing psychotic relapse. In this double-blind study, patients were randomly assigned to either continue treatment with fluphenazine decanoate given every 2 weeks (continuous treatment, $n=18$ ) or be switched to daily pimozide equivalent given 4 times a week (intermittent treatment, $n=16$ ) [160]. Relapse rates over the next 9 months were similar in both groups. A second prospective study was a 6-month, double-blind, controlled trial in outpatients with schizophrenia stabilized for $\geq 3$ months on oral antipsychotic given once daily [161]. The patients were randomly assigned to either treatment as usual $(n=$ 18 ) or the same daily dose given orally every other day $(n=17$; risperidone $=6$, olanzapine $=11)$. Over the 6-month interval, symptom exacerbation and number of hospital admissions were similar in both groups. Thus, the 17 patients who had a 50\% reduction in their mainte-

Psychother Psychosom 2017;86:189-219 
nance dose given as alternate-day treatment (the "extended dosing" group) had similar relapse rates compared to those who kept taking their treatment as usual once a day [161]. However, reduction in the maintenance dose on one hand and continuous versus intermittent treatment on the other were confounded. To directly evaluate the effects of continuous versus intermittent antipsychotic treatment, a study would have to give the same "equivalent" dose daily versus every other day (e.g., 2 mg risperidone/day once daily versus $4 \mathrm{mg}$ risperidone every other day). "Extended dosing" by giving treatment every other day is one strategy to reduce antipsychotic dose by $50 \%$. The authors did not mention the length of prior antipsychotic treatment or the prior daily milligram dose of the 3 medications taken (risperidone, olanzapine, and loxapine). It is likely that the $\mathrm{D}_{2}$ occupancy was lower than the narrow therapeutic window of $65-72 \%$ found by Kapur et al. [138] for the acute/subacute phase and for first-episode schizophrenia. The McCreadie study [160] is more interesting in this respect since patients received a daily dose of oral pimozide 4 times a week (Monday to Thursday; intermittent dosing strategy), which was equivalent to the previous maintenance dose of LA injectable fluphenazine decanoate; intermittent continuous dosing strategy), thus testing the concept of intermittent antipsychotic treatment to achieve minimum therapeutic dosing and prevent dopamine supersensitivity.

Similarly, Tsuboi et al. [162] conducted a single-blind, randomized, prospective, 1-year study including patients treated with oral olanzapine $(n=34)$ and oral risperidone $(n=34)$. Patients were stabilized for 6 months before entering the study. Patients were randomly assigned to receive either a treatment regimen producing continuous blockade of $\mathrm{D}_{2}>65 \%$ or a treatment regimen producing noncontinuous receptor blockade $>65 \%$. The continuous $\mathrm{D}_{2}$ blockade group had an estimated $\mathrm{D}_{2}$ occupancy $>65 \%$ at trough and the noncontinuous blockade group had an estimated peak level of $\mathrm{D}_{2}$ occupancy $>65 \%$ with an estimated trough level of $<65 \%$. The noncontinuous group had target doses of $7.1 \mathrm{mg}$ olanzapine/day and $1.9 \mathrm{mg}$ risperidone/day versus 10.4 and $3.4 \mathrm{mg} /$ day for the continuous group, respectively, the latter producing $>65 \%$ of estimated $\mathrm{D}_{2}$ occupancy. The authors did not find differences between both treatment regimens regarding the prevention of psychotic relapses. Again, here we have low- versus higher-dose maintenance treatment. However, the dosing interval of both drugs is not mentioned, and concomitant medications are not reported. The only information is "choice of dose at the discretion of the subject's physician on record." Finally, we do not think that the study by Tsuboi et al. [162] is strictly a comparison of continuous versus noncontinuous but also low- versus high-dose treatment.

In addition, a PET study by Nyberg et al. [163] showed that continuous $\mathrm{D}_{2}$ receptor blockade $>65 \%$ was not necessary to prevent psychotic relapse. The study included 9 schizophrenic outpatients stabilized on haloperidol decanoate given intramuscularly every 4 weeks [163]. Despite an average fall of $52 \%$ in $\mathrm{D}_{2}$ receptor occupancy at the end of the injection interval compared to the occupancy level 1 week after injection, patients continued to be stable. Uchida and Suzuki [164] came to the same conclusion in their review of all PET and single photon emission tomography studies of LA injectable antipsychotics. They found that the CNS effects as measured by $\mathrm{D}_{2}$ receptor occupancy of LA injectable antipsychotics can persist for several months, and, as such, these medications may be administered at dosing intervals greater than those recommended in product monographs. The Uchida and Suzuki [164] review included a total of 14 studies with LA injectable FGAs (haloperidol decanoate, $n=11$, and fluphenazine decanoate, $n=3$ ), and 4 studies with LA injectable SGAs (LA injectable risperidone, $n=3$, and LA injectable olanzapine pamoate, $n=1$ ). Lee et al. [153] reached similar conclusions in their 2015 review of the pharmacokinetic data of LA injectable SGAs available in Canada and the USA (LA injectable aripiprazole, olanzapine, risperidone, and 1- and 3-month formulations of paliperidone palmitate).

It should be noted that the clinical studies on intermittent or extended dosing cited here included small numbers of patients. Further clinical studies with larger samples are needed. In addition, future studies must also be designed so that minimal therapeutic dose and intermittent dosing are not confounded, thus allowing a dissociation of effects due to dose versus mode of administration.

In summary, continuous occupancy of $\mathrm{D}_{2}$ receptors might not always be necessary to trigger the signaling cascades that underlie the antipsychotic effect. In parallel, the work reviewed here, including preclinical findings $[9,11,154]$, also suggests that sustained antipsychotic treatment above the optimal $\mathrm{D}_{2}$ occupancy threshold for maintenance treatment (which appears lower than for acute and first-episode schizophrenia defined by Kapur [138]) could trigger changes that might be detrimental to the patient. This would include tolerance to therapeutic effects and SP. In parallel, work conducted in animals suggests that intermittent dosing would prevent dopamine supersensitivity $[9,11,154]$. Both the clinical and animal studies reviewed here suggest that an explo- 
ration of intermittent dosing strategies in patients is needed. LA injectable antipsychotics can also be given so as to produce intermittent dosing, taking into account the clinical recommendations of Lee et al. [153] and Uchida and Suzuki [164]. Intermittent dosing involves that $\mathrm{D}_{2}$ occupancy levels be high and then low, with each state maintained for approximately equivalent periods of time. Intermittent dosing should be one way to achieve the minimum therapeutic dose and prevent SP. Thus, LA injectable antipsychotics should not be increased rapidly to mask TD or SP except for palliative treatment in TR patients. However, one should avoid intermittent dosing defined as "targeted" antipsychotic treatment. This involves lengthy intervals without treatment and waiting for prodromal symptoms to reappear before restarting antipsychotic drug treatment. Such approaches were reviewed recently and they turned out to be disastrous for patients [161], since this "targeted" approach led to increased relapse episodes and poor outcomes. Instead, intermittent interval dosing, as used in our animal studies $[9,11,154]$ and as explored in patients by Remington et al. [161], should be investigated further. This would involve intermittent antipsychotic administration with short interdosing intervals (e.g., for oral medication: weekends off and then treatment on Monday to Thursday, as in the McCreadie study [160]). Importantly, the interdosing interval must be long enough to permit peaks and troughs in brain levels of antipsychotic/ $\mathrm{D}_{2}$ receptor occupancy. We predict that this enables some level of normal dopamine-mediated neurotransmission to occur in between peaks of $\mathrm{D}_{2}$ receptor blockade by antipsychotics, thus avoiding the neuroadaptations that lead to dopamine supersensitivity $[165,166]$. The interdosing interval to achieve peaks and troughs in antipsychotic brain levels will be a function of the $t_{1 / 2}$ of the antipsychotic. For instance, the length of the interdosing interval would be longer for LA antipsychotics and comparatively shorter for short-acting antipsychotics. Finally, while threshold levels of $\mathrm{D}_{2}$ occupancy have already been established for first-episode schizophrenia and acute treatment [138], they must still be established for maintenance treatment.

\section{Choice of the Antipsychotic}

Use of SGAs at Doses Associated with Less Movement Disorders

Most SGAs have been reported to be efficacious at doses that are associated with less movement disorders, including parkinsonism and TD compared to FGAs [1, 167], and less dysphoric responses [1, 145]. FGAs, that induce less movement disorders (thioridazine, pimozide, and benzamides: sulpiride, amisulpride, metoclopramide, cisapride, and remoxipride) were found to have significant cardiac and pro-arrhythmic effects, which led to their restricted use (US boxed warning), withdrawal, or nonapproval in several countries (Table 5). One common feature of SGAs is that they are less likely than FGAs to invoke overt drug-induced movement disorders and behavioral dopamine supersensitivity $[1,10,12]$. Most SGAs can have antipsychotic effects at low doses, potentially explaining the lower prevalence of movement disorders with SGAs compared to FGAs [1]. This was demonstrated with risperidone, where at a specific dose, the movement disorder profile is not different from that of haloperidol [169]; severe parkinsonism was observed in patients treated with $>30 \mathrm{mg}$ olanzapine/day [Chouinard G, pers. observation] and $16 \mathrm{mg}$ iloperidone/day [Chouinard G: Iloperidone study ILPB205 in hospitalized schizophrenic patients 1994-96, unpubl. study].

The lower incidence of movement disorders, overt rebound psychosis, or SP associated with SGAs could involve antipsychotic effects at the $5-\mathrm{HT}_{2 \mathrm{~A}}$ receptor. Antipsychotics with high affinity for $5-\mathrm{HT}_{2 \mathrm{~A}}$ are less likely to induce overt rebound psychosis or SP compared with $\mathrm{D}_{2}$ antagonists without high affinity for $5-\mathrm{HT}_{2 \mathrm{~A}}$. However, data presented from 3 studies of SP in schizophrenic patients treated with SGAs [34-36] (online suppl. Table 2, see list of SGAs), and the 2 studies by Fallon and others $[37,38]$ (SGAs not specified) suggest that SP persists even when patients are treated with SGAs. The persistence of SP becomes more evident in patients with a history of long-term treatment [34-36]. Quetiapine has a high incidence of overt SP [39] even though it induces few movement disorders and low prolactin increases, possibly due to transiently high $\mathrm{D}_{2}$ occupancy [122] and its loose binding to $\mathrm{D}_{2}$ receptors [39]. This is confirmed by the review of studies by Cerovecki et al. [94] on the switch to quetiapine, which showed an improvement in extrapyramidal movement disorders and prolactin increase after the switch. In animals, blockade of $5-\mathrm{HT}_{2 \mathrm{~A}}$ by the selective $5-\mathrm{HT}_{2 \mathrm{~A}}$ receptor antagonist MDL100,907 or by the unselective $5-\mathrm{HT}_{2}$ blocker ritanserin reverses the behavioral manifestations of antipsychotic-induced dopamine supersensitivity [8]. This beneficial effect is seen in patients with TD, but less in those with SP, even after long-term administration of SGAs with selective $5-\mathrm{HT}_{2 \mathrm{~A}}$ receptor antagonist properties $[1,34-38,84]$. The only exception appears to be clozapine [170]. It should be kept in mind

Supersensitivity Psychosis

Psychother Psychosom 2017;86:189-219 
that it might be difficult to obtain reliable pharmacological profiles for clozapine and quetiapine because of drug solubility and administration constraints [159]. In addition to $5-\mathrm{HT}_{2 \mathrm{~A}}$ receptor blockade, other mechanisms have been proposed to explain the lower incidence of drug-induced movement disorders with SGAs: blockade of muscarinic M1 postsynaptic blockade of $\alpha_{2 C}$ and of $5-\mathrm{HT}_{2 \mathrm{C}}$ receptor blockade [see Cerovecki et al. 94 for review].

\section{Avoiding the Use of Antipsychotics That Increase the} Risk of SP

FGAs, in particular fluphenazine $[26,171,172]$ and perphenazine $[26,172]$, which have human cloned $\mathrm{D}_{2}$ binding affinities higher than that of haloperidol, are no longer recommended in the treatment of psychotic disorders [1] and should be avoided. The SGA quetiapine, which binds more loosely to the $\mathrm{D}_{2}$ receptor [39], was found to have an increased incidence of SP $[39,173]$ and rebound withdrawal reactions including rebound psychosis [1]. Clozapine was also reported to have a higher incidence of rebound psychosis or rapid-onset withdrawal psychosis [33], but its overall beneficial effects make the drug unique for drug-resistant and suicidal patients [146, 174].

Quetiapine also deserves special consideration because of its efficacy in several psychiatric disorders [117, 118]. For nonpsychotic disorders and major depression [118], IR or XR quetiapine $\leq 150 \mathrm{mg} /$ day [117] can be given for 2 months as adjunctive or monotherapy, during which time the quetiapine dose is kept $\leq 150 \mathrm{mg} /$ day. The dose of IR and XR quetiapine can then be decreased to see if rebound anxiety and/or insomnia appear. Rebound anxiety and rebound insomnia are distressing but easy to identify. Criteria C1-C7 in Table 3 and criterion B for SSRI and SNRI rebound withdrawal [41] will help to identify rebound syndromes. In the treatment of psychotic and bipolar disorders with quetiapine, the same principles listed in Table 5 apply as for the prevention of rebound psychosis: early detection of TD and abnormal movements, minimal therapeutic doses, and/or alternate dosing. The problem is to decrease quetiapine after continuous use for $>2$ months. However, quetiapine given at a dose $\leq 150 \mathrm{mg} /$ day for a period of 2 months can be safe for rebound and withdrawal [117]. Alternate dosing will permit early detection of rebound anxiety, insomnia, and psychosis associated with quetiapine (Table 5).

The use of FGAs might also increase the risk of SP relative to SGAs. Work in animal models shows that at equivalent doses and modes of treatment, long-term exposure to haloperidol produces dopamine receptor su- persensitivity, while exposure to olanzapine or ziprasidone does not $[10,12,156,175-177]$. The two classes of antipsychotics have common but also different pharmacological properties. SGAs generally bind more loosely to $\mathrm{D}_{2}$ receptors than FGAs [178]. This could allow more endogenous dopamine to gain access to its receptors during treatment with SGAs, thus avoiding dopamine SP. Compared to FGAs, SGAs also have higher affinities at several serotonin receptor types [179]. As mentioned above, serotonin receptors, in particular the $2 \mathrm{~A}$ subtype, are involved in antipsychotic-induced dopamine supersensitivity [8].

Special Considerations for Dopamine Partial Agonists and First-Episode Psychotic Disorders

High-affinity $\mathrm{D}_{2}$ receptor partial agonists, such as aripiprazole, should be given special consideration in the prevention of SP. Chronic treatment with aripiprazole was found to reverse dopamine supersensitivity in animal models, potentially by reducing upregulated $\mathrm{D}_{2}$ receptors [44]. In vitro data suggest that aripiprazole is a functionally selective $\mathrm{D}_{2}$ ligand rather than a simple partial agonist [180-182] and does not produce significant internalization of $\mathrm{D}_{2}$ receptors. Indeed, an emerging view is that aripiprazole can cause a wide range of pharmacological effects at the $\mathrm{D}_{2}$ receptor, going from receptor inactivation to stimulation of different functions [181]. To achieve this, the antipsychotic is thought to interact with the receptor and trigger conformational changes different from those evoked by dopamine itself, depending on elements including endogenous dopamine levels and receptor signaling status [181]. This would allow aripiprazole to selectively modulate signaling pathways downstream of the $\mathrm{D}_{2}$ receptor and thus evoke a range of effects at the receptor. In addition, aripiprazole has other receptor actions, including partial and inverse agonist effects at $5-\mathrm{HT}_{2}$ receptors [183]. In this regard, it is noteworthy that Charron et al. [8] have shown that pharmacological blockade of $5-\mathrm{HT}_{2}$ receptors reverses antipsychotic-induced dopamine receptor supersensitivity.

However, aripiprazole should be used with caution in patients with SP and patients treated with high doses of antipsychotics [36]. In patients with a dopamine supersensitive state, $\mathrm{D}_{2}$ ligands with agonist properties such as aripiprazole can increase SP by binding to $\mathrm{D}_{2}$ receptors that are in an unblocked state and producing greater agonistic effects [36, 184]. In the study by Takase et al. [36], SP was proposed to explain the exacerbation of psychosis by aripiprazole during the switch from SGAs to aripiprazole. This finding led us to add aripiprazole-induced psy- 
chotic exacerbations as a risk factor in criterion D4 for SP (Table 4). Thus, when aripiprazole is added to an ongoing antipsychotic treatment, it should be titrated very gradually to a dose $<20 \mathrm{mg} /$ day to prevent exacerbation of psychotic symptoms [36]. However, when aripiprazole is given as monotherapy or in combination therapy for first-episode psychotic disorders, or before SP develops, it may prevent SP and reduce idiopathic psychosis and drug resistance. It should be noted that aripiprazole is associated with a low risk of TD [185] and relapse [186].

According to research by Iyo et al. [4] and Takase et al. [36], $\geq 20 \mathrm{mg}$ aripiprazole/day induces psychotic exacerbation in patients with SP. This is presumably because the agonistic effects of aripiprazole also increase with increasing dose because it now binds to more $\mathrm{D}_{2}$ receptors in the case of overt SP and uncovers masked SP in patients treated with high-dose antipsychotics [36]. Thus, aripiprazole doses $<20 \mathrm{mg} /$ day must be used preferably before SP develops, e.g., early in the drug treatment of psychosis, either as adjunct or monotherapy but also for TR schizophrenia with SP at low-dose monotherapy aripiprazole LAI $300 \mathrm{mg} \mathrm{1/4}$ twice monthly equivalent to $6,2625 \mathrm{mg}$ aripiprazole/day p.o. [187] with lamotrigine as adjunctive antiseizure drug, initiated at $2.5-80 \mathrm{mg} /$ day [Peretti and Chouinard, in preparation].

\section{Guidelines for SP Treatment}

There have been 2 therapeutic approaches for the treatment of SP. One is to prevent and reduce the increase in $\mathrm{D}_{2}$ receptor density, and the other is more symptom and relapse oriented, and consists of treatments that reduce psychotic symptoms in patients with SP, with or without treatment resistance.

\section{Antiseizure Drugs}

In the era of FGAs, the first drug treatment given for SP consisted of adjunctive antiseizure drugs to antipsychotics for TR schizophrenia with SP $[69,188]$. In this first study ( $n=43$ separate trials of antiseizure drugs in 35 patients), adjunctive antiseizure drugs were valproate (valproic acid), carbamazepine, or phenytoin [69]; 51\% $(18 / 35)$ of the patients were rated by the treating nurses and psychiatrists as being "much" or "very much" improved on the Clinical Global Impression (CGI) of Improvement. The rationale for using adjunctive antiseizure therapy has been described in 2 prior publications [69, 188]. One of us (G.C.) had a consultation from the head

Supersensitivity Psychosis
(Pierre Gloor) of the EEG laboratory of the Montreal Neurological Institute, concerning which antipsychotic would be best to uncover silent epileptic focus in the EEG laboratory. At that time, lowering seizure threshold by FGAs was common practice in EEG laboratories. At the same time, we were looking for a treatment to help hospitalized schizophrenic patients who had severe SP upon antipsychotic switch [14]. We hypothesized the induction of psychosis by the continuous and repeated administration of a seizure subthreshold-lowering drug, with progressive increase in the duration of psychosis and symptom generalization, e.g., an antipsychotic-induced kindling producing SP and responding to antiseizure drugs $[69,188]$; antipsychotic kindling effects would be similar to the subthreshold electric shock kindling producing convulsions discovered by Goddard et al. [189] in 1969, to levodopa kindling inducing behavioral changes proposed by Klawans group [190] in 1978, and cocaine kindling proposed by Post et al. [191] in 1975. The first patient (case 1) [14] was treated successfully with phenytoin. We then give valproate and carbamazepine for both preventing and treating SP [1]. In the era of SGAs, antiseizure drugs (valproic acid, lamotrigine, and gabapentin) are still given early in the treatment of schizophrenia to potentiate the therapeutic effects of antipsychotics, to prevent the need for high antipsychotic doses, and to avoid SP and treatment resistance [1, 192, 193]. We believe that it may be the best approach to keep SGAs at low doses, thus preventing a potential increase in $\mathrm{D}_{2}$ receptor number or function [1]. Unfortunately, controlled, double-blind studies have been difficult to initiate, in part because several schizophrenic drug-resistant patients with SP are already taking antiseizure drugs.

\section{Clozapine, Asenapine, Blonanserin, and}

Electroconvulsive Therapy

In the era of FGAs, SGAs were investigated as a potential treatment for SP and treatment resistance. The first clinical trial included 11 schizophrenic patients with treatment resistance and SP: 6 were treated with risperidone and 5 with clozapine [194]. All prior antipsychotics were discontinued, and patients were treated for a mean period of 11 months. In this open-label study, both SGAs were efficacious in the treatment of SP [194]. These SGA drugs were considered as palliative treatment as was shown later by the 3 recent studies [34-36] in patients treated with SGAs $(n=505)$ (the SGA list is presented in online suppl. Table 2 and does not include clozapine).

Clozapine and electroconvulsive therapy (ECT) are also considered as potentially relevant treatments for SP due to their effectiveness in patients with TR schizophre-

Psychother Psychosom 2017;86:189-219 
nia including patients treated with other SGAs [195]. The mechanism underlying the effectiveness of clozapine for TR schizophrenia remains unclear but appears different from its anti- $\mathrm{D}_{2}$ effects. However, when clozapine is withdrawn or discontinued, complex effects of clozapine on upregulated $\mathrm{D}_{2}$ receptors may produce severe psychotic symptoms at times unresponsive to reinstitution of clozapine. Usually, a rebound psychosis or transient SP can appear rapidly [33]. As for ECT, it can transiently increase striatal dopamine release [196] and attenuate both haloperidol-induced increases in $\mathrm{D}_{2}$ receptor density and behavioral supersensitivity to the dopamine agonist apomorphine [45]. As mentioned above, the link between changes in $\mathrm{D}_{2}$ receptor number/function and SP remains to be determined. This issue notwithstanding, it is possible that ECT improves SP through normalization of upregulated $\mathrm{D}_{2}$ receptors.

Recently, Nakata et al. [197] reported a naturalistic study of 15 schizophrenic patients with treatment resistance and SP given clozapine in addition to ongoing antipsychotic treatment after clozapine approval in Japan. After an average of 2.5 years on this treatment, 13 of the 15 TR patients with SP did not have any further SP episodes, 1 patient with persistent TD continued to have SP episodes, and another patient presented immediate rebound psychosis after discontinuation of $600 \mathrm{mg}$ clozapine/day for 3.94 years. The beneficial effects on TD seen in 4 of 5 patients are consistent with previous TD studies by Louzã et al. [198].

Asenapine is an alternative for the treatment of SP; it is an SGA with partial agonist properties at 5- $\mathrm{HT}_{1 \mathrm{~A}}$ [199] and potent anti-5- $\mathrm{HT}_{2}$ activity relative to anti- $\mathrm{D}_{2}$ effects [200]. Asenapine has been reported to be effective in the treatment of a patient with SP induced by ziprasidone [201]. In addition, asenapine was found to prevent clozapine rebound withdrawal after abrupt discontinuation of $250 \mathrm{mg}$ clozapine/day [202]. Cerovecki et al. [94] reported that switching to asenapine might be advantageous for "weight gain, metabolic disturbances or prolactin increase." Asenapine is highly lipophilic when given sublingual $[203,204]$. Blonanserin is an alternative for the treatment of SP; it is an SGA with a unique profile. It has high $\mathrm{D}_{2}$ binding affinity $[205,206]$ with high lipophilicity and stable central $\mathrm{D}_{2}$ receptor occupancy $[207,208]$. This profile suggests potential benefits of using blonanserin in the treatment of schizophrenic patients with treatment resistance and SP [4]. Eight consecutive unstable patients with TR schizophrenia and SP were treated with blonanserin [208] initially as an add-on therapy and then as antipsychotic monotherapy. Thus, although data on the issue re- main limited, both asenapine and blonanserin could be interesting alternatives to clozapine as monotherapy in the treatment of schizophrenia with treatment resistance and SP, with adjunctive antiseizure drugs [208].

\section{High-Potency Injectable SGAs with Long $t_{1 / 2}$}

Once SP has developed, SGAs with long $t_{1 / 2}$ such as LA injectable antipsychotics, which have continuous blockade of $\mathrm{D}_{2}$ receptors, should stabilize blockade of $\mathrm{D}_{2}$ receptors within optimal therapeutic ranges, and minimize fluctuations above and below therapeutic levels $[34,140]$. $t_{1 / 2}$ plays an important role in the appearance and exacerbation of psychotic symptoms in patients with SP, since the number of $\mathrm{D}_{2}$ receptors blocked by the drug may fluctuate below the optimal therapeutic range when plasma and brain levels fall [4]. In addition, potent SGAs with high affinity for $\mathrm{D}_{2}$ receptors should be more efficacious to prevent psychosis uncovered by stress. However, as mentioned, animal research shows that maintaining continuous $\mathrm{D}_{2}$ receptor occupancy levels promotes dopamine receptor supersensitivity, while fluctuation in occupancy levels by antipsychotics is protective $[9,11,154]$. At first, before SP develops and once the patient is stable, intermittent treatment strategies, which permit noncontinuous receptor blockade, should be preferred when therapeutic care and follow-up are available to patients.

\section{LA Injectable Risperidone}

LA injectable risperidone can have greater efficacy in schizophrenic patients with treatment resistance and SP compared to patients with treatment resistance without SP (online suppl. Table 2) [34, 84, 140]. One explanation is that treatment resistance is caused by SP [1]. These results suggest that a reduction in fluctuations of drug plasma levels improves both SP positive and negative symptoms and movement disorders. On the other hand, while the continuous blockade of $\mathrm{D}_{2}$ receptors by LA injectable risperidone could explain the observed improvements in SP patient outcomes, it cannot be excluded that this might be due to the pharmacological action of the antipsychotic and/or to a change in the peak levels of striatal $\mathrm{D}_{2}$ receptor occupancy after the addition of LA injectable risperidone. In addition, the mean antipsychotic dose expressed in chlorpromazine equivalent (in $\mathrm{mg} /$ day) did not change before and after 12 months of treatment. This suggests that there was no change in the $\mathrm{D}_{2}$ receptor density in treated patients. Thus, LA injectable risperidone is a symptom-oriented treatment that can reduce SP symptoms, SP episodes, and movement disorders over a 1- to 2-year period $[34,140]$.
210

Psychother Psychosom 2017;86:189-219 DOI: $10.1159 / 000477313$
Chouinard/Samaha/Chouinard/Peretti/ Kanahara/Takase/Iyo 


\section{Guidelines for the Management of Antipsychotic Withdrawal}

\section{Identifying the Withdrawal Syndrome and}

Antipsychotics That Promote Withdrawal Symptoms

Management of antipsychotic withdrawal should begin by differentiating the type of withdrawal syndrome from relapse and recurrence of the illness. Criteria for each antipsychotic withdrawal syndrome are listed in Tables 1-4. Within each class of CNS drugs, there is a problematic drug that permits early identification of a withdrawal syndrome; often, it is the same drug that led to initial observation of the syndrome. The ultrashort and short-lasting effects of cocaine, heroin, alcohol, triazolam, alprazolam, lorazepam, and quetiapine are thought to be responsible for their withdrawal reactions, including rebound anxiety [103] and insomnia [105], and contributing to substance use disorders $[1,41,90]$. Additional mechanisms have been proposed to explain specific withdrawal syndromes: loose binding at receptor sites [120] for quetiapine rebound psychosis [26, 39, 120], high potency at the $\mathrm{D}_{2}$ receptor [26] for fluphenazine and perphenazine for SP $[1,14]$, potency at multiple receptors for paroxetine rebound depression and persistent postwithdrawal disorders [109], and sometimes a combination of 2 mechanisms for clozapine rebound psychosis $[1,120]$. In general, benzodiazepines (triazolam, alprazolam, and lorazepam) should not be given for more than 3 months and quetiapine $>150 \mathrm{mg} /$ day should not be given for more than 2 months because of difficulties in discontinuing these drugs.

\section{Gradual Dose Reduction and Minimal Therapeutic \\ Dose}

Silvestri et al. [18] showed that FGAs (haloperidol) and SGAs (risperidone and olanzapine) increased $\mathrm{D}_{2}$ receptor binding with great variability (from - 14 to $98 \%$ ) in schizophrenic patients withdrawn for 14 days from long-term antipsychotic treatment. Kapur et al. [138] found a wide range of $\mathrm{D}_{2}$ occupancy (38-87\%) in first-episode schizophrenic patients treated with haloperidol. These sources of variability are an additional difficulty in finding the minimal therapeutic dose especially for maintenance treatment. To discontinue an antipsychotic, we recommend gradual dose reduction over a long period of time/ over several months when clinically appropriate. According to most studies $[1,15,17,20,29]$, even with gradual dose reduction, antipsychotic withdrawal symptoms will still occur; gradual dose reduction will reduce the severity of symptoms [103]. By reducing the dose gradually, a

Supersensitivity Psychosis steady-state plateau will develop, which permits to better distinguish between new symptoms, rebound, postwithdrawal, recurrence, and relapse. Of note, gradual dose reduction may reduce new and rebound symptoms, including rebound psychosis and reversible withdrawal SP, but has no effect on postwithdrawal disorders. For antipsychotics and other CNS drugs, dose reduction should be done gradually and with adjunctive antiseizure [1] and LA drugs.

\section{Adjunctive LA Injectable SGAs}

Recommendations for withdrawal of alcohol, opiate, benzodiazepine, and SSRI/SNRI $[41,90,114]$ should apply for antipsychotic discontinuation/dose reduction: the use of adjunctive long $t_{1 / 2}$ drugs such as LA injectable SGAs and antiseizure drugs. Given the evidence for the risk of rebound withdrawal with quetiapine, thought to be related to dopamine, noradrenergic, and cholinergic/ antihistaminic rebound receptor supersensitivity, due its short $\mathrm{t}_{1 / 2}$ at receptor sites [1], we recommend giving quetiapine $\leq 150 \mathrm{mg} /$ day as adjunctive therapy instead of monotherapy for psychoses including bipolar disorders unless patient could be treated with monotherapy $\leq 150$ $\mathrm{mg}$ /day without further dose increase $[39,173]$. When giving quetiapine as adjunctive or monotherapy during 2 months and more, attempts to decrease the dose with alternate dosing intervals Monday to Friday or Monday to Thursday, or with a gradual decrease in the daily dose of quetiapine are recommended to identify the presence of rebound syndromes.

\section{Adjunctive Treatment to Achieve Minimal Therapeutic Dose}

Giving low doses of antipsychotic, decreasing the length of maintenance treatment, using adjunct treatments, and reducing stressful life events should prevent or attenuate the development of neuroadaptations that lead to SP and therapeutic tolerance. After 2 years of antipsychotic treatment, adjunctive drug treatment and therapies should be considered whenever there is a need to continue antipsychotics. We previously proposed antiseizure drugs for the prevention of antipsychotic withdrawal $[1,69,209]$. Lamotrigine at low doses is beneficial as adjunctive therapy to facilitate a decrease in medication and a minimal therapeutic dose [1]; other antiseizure drugs, valproic acid, and gabapentin, are also useful [192]. 


\section{Limitations}

Studies on long-term persistent side effects are difficult to carry out in part because of significant differences in the prevalences reported in studies and countries often related to prescribing habits and patient adherence to treatment. This also remains a challenge for long-term studies on TD. Despite validated methods to diagnose TD based on similarities with L-DOPA-induced dyskinesia, the existence of TD was contested $[1,210,211]$. TD was once considered to be a manifestation of schizophrenic motor mannerisms existing before FGAs. Several placebo-controlled studies have also failed to reach a consensus regarding the treatment of TD $[1,212,213]$. Diagnosing and treating SP might likely be just as challenging. An added difficulty with the antipsychotic-induced SP is that the symptoms can be confounded with those of the illness itself. However, patients themselves, when they are in remission, distinguish between symptoms linked to original illness or associated with drug withdrawal $[14,30]$.

Furthermore, not all drugs prescribed for the same indications produce persistent drug disorders at the same intensity and prevalence. This might lead to believe that these persistent withdrawal disorders do not exist. This is evident with SSRIs [41] and benzodiazepines. For instance, because rebound insomnia was seen most often with triazolam and less with other benzodiazepines [105], there were doubts about the existence of the benzodiazepine rebound syndrome as shown by the differences in triazolam restrictions between countries. Hong Kong restricted triazolam use in 1991 and extended the restrictions to all benzodiazepines in 1992 [112]. Triazolam was first suspended in the Netherlands (1979) and later definitively in the UK (1999) [214]. In the USA, dose restrictions of triazolam were imposed [112]. Triazolam is still marketed in the USA, with a dosing labeling revised in 1991 [112]. Similarly, paroxetine induces persistent postwithdrawal disorders at a high prevalence and severity compared to other SSRIs [41]. If paroxetine had not been introduced into clinical practice, persistent SSRI withdrawal disorders may not have been found [41]. It is also the case for fluphenazine; if it had not been introduced, we may not be discussing SP. However, for antipsychotics, there was pharmacological evidence for dopamine supersensitivity [26]. Only long-term ( $>5$ years) follow-up of outpatients, preferably with the same therapists, can help to better understand persistent druginduced disorders. In our opinion, these studies are needed for both SSRI/SNRI antidepressants and antipsychotics.
As already mentioned, there are no or few long-term ( $>5$ years) controlled studies of efficacy and treatmentemergent symptoms or side effects with SGAs. One such study was a 4-year double-blind randomized study of risperidone and haloperidol in first-episode schizophrenia [215]: $60.7 \%$ (337/555) of patients completed the study, $57.9 \%(167 / 278)$ in the risperidone group, and $63.5 \%$ (176/277) in the haloperidol group. Patients were treated with the study medication for a median of 0.53 years (range 2 days to 4.2 years) in the risperidone group and for a median of 0.6 years (range $=1$ day to 4.15 years) in the haloperidol group [215]. As can be seen, median values for the duration of drug treatments are very low for a 4 -year randomized study with a median of 0.53 years (or 6.3 months) in the risperidone group and a median of 0.6 years (or 7.3 months) in the haloperidol group [215]. Thus, one could understand why we describe in this paper open-label prospective, naturalistic, or retrospective studies of drug treatments for SP with focus on completer rates, duration of treatment with trial medications, and dose reduction of concomitant SGAs. The results in terms of completer rates and length of drug intake in the 4-year randomized study of Schooler et al. [215] illustrate the difficulties in carrying out studies over 5 years in the treatment of schizophrenia and more so in the treatment of persistent postwithdrawal disorders.

For other classes of drugs such as the statins, as early as 2001 concerns arose about their efficacy in assuming that all drugs of the same family are interchangeable, and about the risks overweighing the benefits; at that time only 2 statins had follow-up studies over 5 years [216]. The authors recommend long-term studies with each specific drug of a therapeutic class [216]. With antipsychotics, these studies are rare even for efficacy, which is another limitation to study long-term treatment-persistent emergent symptoms or side effects.

Further limits come from the lack of appropriate controlled withdrawal studies of LA injectable antipsychotics after 5 years of administration. A recent review of product monographs of all second-generation LA injectable antipsychotics showed that studies to estimate the administration dosing interval do not exist or are not available either for LA injectable risperidone, aripiprazole, or olanzapine, or 1- and 3-month formulations of paliperidone palmitate, and the review concluded that "off-label prescribing practices may actually produce better clinical outcomes than if decisions were based on the product monograph data alone" [153]. The authors noted that $t_{1 / 2}$ (terminal plasma half-life) reported in monographs were based on studies using small sample sizes, a subset of par- 
ticipants with unspecified characteristics, pooling data of all dosage strengths, and times to steady-state determined with visual inspection of concentration-time curves, even worse with the triphasic release of risperidone microspheres "The reported half-life of 3-6 days has no clinical relevance" [153]. A recent example is the 3-month formulation of paliperidone palmitate. The Janssen Canadian monograph of prolonged-release paliperidone palmitate requires that before receiving this new formulation patients be stable for at least 4 months on the paliperidone palminate 1-month formulation without adequate available knowledge of the duration of action of 1-month paliperidone palmitate [153]. The recent introduction of injectable (prolonged-release) paliperidone palmitate with a proposed 3-month duration of action will further complicate the issues of studying withdrawal and intermittent versus continuous treatment regarding the minimum therapeutic maintenance dose.

Further limitations come from the lack of a consensus on the long-term side effects induced by antipsychotics; this is particularly true for SP [1] but also for antipsychotic-induced metabolic disorders [217].

\section{Conclusion}

FGAs and SGAs provided major therapeutic advances for idiopathic and nonidiopathic psychotic disorders, but long-term $\mathrm{D}_{2}$ receptor blockade by these medications can lead to drug-induced SP and movement disorders. These effects are potentially linked to an increase in $\mathrm{D}_{2}$ receptor density and $\mathrm{D}_{2}$-mediated signaling evoked by chronic antipsychotic treatment (Fig. 1). Patients with SP are often given higher doses of antipsychotics to block the potentially upregulated $\mathrm{D}_{2}$ receptors. This will promote further increases in $\mathrm{D}_{2}$ receptor density/function and therapeutic tolerance (decreased therapeutic effects of previously efficacious doses and the need to increase dosages to maintain similar beneficial effects). SP can be overt during drug withdrawal and masked during drug treatment, which explains therapeutic tolerance (i.e., previously efficacious doses of antipsychotics can no longer mask or treat psychotic symptoms). The proposed diagnostic criteria for withdrawal will help clinicians distinguish between the 3 types of withdrawal relapse and recurrence of the original illness. When the antipsychotic dose is increased to maintain a therapeutic effect in patients with SP, this is often associated with the emergence of TR psychosis. The risk of SP should be considered not only in adjusting the minimal therapeutic dose during mainte-

Supersensitivity Psychosis nance treatment, but also early in the treatment of firstepisode schizophrenia and TR schizophrenia. Mild or borderline movement disorders of the parkinsonian type are the best predictors of SP and TD. The early detection of movement disorders can be used to prevent SP and TD. We have also highlighted that withdrawal following postdrug discontinuation/dose reduction/switch of medications can occur with all CNS drugs including antipsychotics. Finally, we have proposed several treatment options to either treat or reduce the likelihood of antipsychotic-induced SP, movement disorders, and treatment resistance. These include adjunctive treatments with antiseizure drugs, as well as intermittent dosing regimens with existing antipsychotic medications. Studies on intermittent dosing intervals for oral and LA injectable antipsychotics are needed to establish the minimal therapeutic maintenance dose, and to avoid increases in $\mathrm{D}_{2}$ receptor number and agonist affinity, which in turn can lead to SP, rebound psychosis, withdrawal psychosis, and drug resistance.

\section{Acknowledgments}

We are grateful to Mister Patrick Castell for the design and illustration of Figure 1.

\section{Disclosure Statement}

The authors declare that over the past 3 years Dr. M. Iyo received grants from Health, Labour, and Welfare for Scientific Research and payments for Guest lectures from Janssen, Sumitomo Dainippon, Otsuka, Eli Lilly Japan, and Meiji Seika, Dr. C.-S. Peretti symposium fees from Janssen, Astra-Zeneca, and Otsuka, and Dr. N. Kanahara honoraria from Janssen, Sumitomo Dainippon, Otsuka, and Eli Lilly Japan, and Dr. M. Takase from Otsuka and Astellas. Dr. G. Chouinard and Dr. V.-A. Chouinard have no conflict of interests to declare. Dr. A-N. Samaha is a consultant for Nektar Therapeutics and holds a salary award from the Fonds de la Recherche du Québec-Santé (award No. 28988).

\section{Author Contributions}

All authors critically reviewed and approved the final version of the paper. 


\section{References}

1 Chouinard G, Chouinard VA: Atypical antipsychotics: CATIE study, drug-induced movement disorder and resulting iatrogenic psychiatric-like symptoms, supersensitivity rebound psychosis and withdrawal discontinuation syndromes. Psychother Psychosom 2008;77:69-77.

2 Lieberman JA, Stroup TS, McEvoy JP, Swartz MS, Rosenheck RA, Perkins DO, Keefe RS, Davis SM, Davis CE, Lebowitz BD, Severe J, Hsiao JK; Clinical Antipsychotic Trials of Intervention Effectiveness Investigators: Effectiveness of antipsychotic drugs in patients with chronic schizophrenia. N Engl J Med 2005;353:1209-1223.

3 Seeman P: Targeting the dopamine D2 receptor in schizophrenia. Expert Opin Ther Targets 2006;10:515-531.

4 Iyo M, Tadokoro S, Kanahara N, Hashimoto T, Niitsu T, Watanabe H, Hashimoto K: Optimal extent of dopamine D2 receptor occupancy by antipsychotics for treatment of dopamine supersensitivity psychosis and lateonset psychosis. J Clin Psychopharmacol 2013;33:398-404.

5 Kane JM: Treatment strategies to prevent relapse and encourage remission. J Clin Psychiatry 2007;68(suppl 14):27-30.

6 Burt DR, Creese I, Snyder SH: Antischizophrenic drugs: chronic treatment elevates dopamine receptor binding in brain. Science 1977;196:326-328.

7 Creese I, Burt DR, Snyder SH: Dopamine receptor binding enhancement accompanies lesion-induced behavioral supersensitivity. Science 1977;197:596-598.

8 Charron A, Hage CE, Servonnet A, Samaha AN: 5-HT2 receptors modulate the expression of antipsychotic-induced dopamine supersensitivity. Eur Neuropsychopharmacol 2015;25:2381-2393.

9 Samaha AN, Reckless GE, Seeman P, Diwan M, Nobrega JN, Kapur S: Less is more: antipsychotic drug effects are greater with transient rather than continuous delivery. Biol Psychiatry 2008;64:145-152.

10 Samaha AN, Seeman P, Stewart J, Rajabi H, Kapur S: "Breakthrough" dopamine supersensitivity during ongoing antipsychotic treatment leads to treatment failure over time. J Neurosci 2007;27:2979-2986.

11 Bedard AM, Maheux J, Levesque D, Samaha AN: Continuous, but not intermittent, antipsychotic drug delivery intensifies the pursuit of reward cues. Neuropsychopharmacology 2011;36:1248-1259.

12 Bedard AM, Maheux J, Levesque D, Samaha AN: Prior haloperidol, but not olanzapine, exposure augments the pursuit of reward cues: implications for substance abuse in schizophrenia. Schizophr Bull 2013;39:692-702.
13 El Hage C, Bedard AM, Samaha AN: Antipsychotic treatment leading to dopamine supersensitivity persistently alters nucleus accumbens function. Neuropharmacology 2015;99: 715-725.

14 Chouinard G: Severe cases of neuroleptic-induced supersensitivity psychosis. Diagnostic criteria for the disorder and its treatment. Schizophr Res 1991;5:21-33.

15 Kirkpatrick B, Alphs L, Buchanan RW: The concept of supersensitivity psychosis. J Nerv Ment Dis 1992;180:265-270.

16 Seeman MV, Seeman P: Is schizophrenia a dopamine supersensitivity psychotic reaction? Prog Neuropsychopharmacol Biol Psychiatry 2014;48:155-160.

17 Seeman P: Schizophrenia and dopamine receptors. Eur Neuropsychopharmacol 2013, 23:999-1009.

18 Silvestri S, Seeman MV, Negrete JC, Houle S, Shammi CM, Remington GJ, Kapur S, Zipursky RB, Wilson AA, Christensen BK, Seeman $P$ : Increased dopamine D2 receptor binding after long-term treatment with antipsychotics in humans: a clinical PET study. Psychopharmacology (Berl) 2000;152:174-180.

19 Chouinard G, Creese I, Boisvert D, Annable L, Bradwejn J, Jones B: High neuroleptic plasma levels in patients manifesting supersensitivity psychosis. Biol Psychiatry 1982;17:849-852.

20 Miller R, Chouinard G: Loss of striatal cholinergic neurons as a basis for tardive and L-DOPA-induced dyskinesias, neurolepticinduced supersensitivity psychosis and refractory schizophrenia. Biol Psychiatry 1993; 34:713-738.

21 Chouinard G, Jones BD: Schizophrenia as dopamine-deficiency disease. Lancet 1978;2:99100

22 Chouinard G, Jones BD: Evidence of brain dopamine deficiency in schizophrenia. Can J Psychiatry 1979;24:661-667.

23 Reith J, Benkelfat C, Sherwin A, Yasuhara Y, Kuwabara H, Andermann F, Bachneff S, Cumming P, Diksic M, Dyve SE, Etienne P, Evans AC, Lal S, Shevell M, Savard G, Wong DF, Chouinard G, Gjedde A: Elevated dopa decarboxylase activity in living brain of patients with psychosis. Proc Natl Acad Sci USA 1994:91:11651-11654.

24 Abi-Dargham A, Rodenhiser J, Printz D, ZeaPonce Y, Gil R, Kegeles LS, Weiss R, Cooper TB, Mann JJ, Van Heertum RL, Gorman JM, Laruelle M: Increased baseline occupancy of D2 receptors by dopamine in schizophrenia. Proc Natl Acad Sci USA 2000;97:8104-8109.

25 Seeman P, Weinshenker D, Quirion R, Srivastava LK, Bhardwaj SK, Grandy DK, Premont RT, Sotnikova TD, Boksa P, El-Ghundi M, O'Dowd BF, George SR, Perreault ML, Mannisto PT, Robinson S, Palmiter RD, Tallerico T: Dopamine supersensitivity correlates with $\mathrm{D} 2^{\text {High }}$ states, implying many paths to psychosis. Proc Natl Acad Sci USA 2005; 102:3513-3518.
26 Seeman P: All roads to schizophrenia lead to dopamine supersensitivity and elevated dopamine D2 ${ }^{\text {High }}$ receptors. CNS Neurosci Ther 2011;17:118-132.

27 George SR, Watanabe M, Di Paolo T, Falardeau P, Labrie F, Seeman P: The functional state of the dopamine receptor in the anterior pituitary is in the high affinity form. Endocrinology 1985;117:690-697.

28 Chouinard G, Jones BD, Annable L: Neuroleptic-induced supersensitivity psychosis. Am J Psychiatry 1978;135:1409-1410.

29 Davis KL, Rosenberg GS: Is there a limbic system equivalent of tardive dyskinesia? Biol Psychiatry 1979;14:699-703.

30 Chouinard G, Jones BD: Neuroleptic-induced supersensitivity psychosis: clinical and pharmacologic characteristics. Am J Psychiatry $1980 ; 137: 16-21$

31 Chouinard G: New nomenclature for druginduced movement disorders including tardive dyskinesia. J Clin Psychiatry 2004;65:9S$15 \mathrm{~S}$.

32 Moncrieff J: Why is it so difficult to stop psychiatric drug treatment? It may be nothing to do with the original problem. Med Hypotheses 2006;67:517-523.

33 Moncrieff J: Does antipsychotic withdrawal provoke psychosis? Review of the literature on rapid onset psychosis (supersensitivity psychosis) and withdrawal-related relapse. Acta Psychiatr Scand 2006;114:3-13.

34 Kimura H, Kanahara N, Komatsu N, Ishige M, Muneoka K, Yoshimura M, Yamanaka H, Suzuki T, Komatsu H, Sasaki T, Hashimoto T, Hasegawa T, Shiina A, Ishikawa M, Sekine Y, Shiraishi T, Watanabe H, Shimizu E, Hashimoto $\mathrm{K}$, Iyo M: A prospective comparative study of risperidone long-acting injectable for treatment-resistant schizophrenia with dopamine supersensitivity psychosis. Schizophr Res 2014;155:52-58.

35 Suzuki T, Kanahara N, Yamanaka H, Takase M, Kimura H, Watanabe H, Iyo M: Dopamine supersensitivity psychosis as a pivotal factor in treatment-resistant schizophrenia. Psychiatry Res 2015;227:278-282.

36 Takase M, Kanahara N, Oda Y, Kimura H, Watanabe H, Iyo M: Dopamine supersensitivity psychosis and dopamine partial agonist: a retrospective survey of failure of switching to aripiprazole in schizophrenia. J Psychopharmacol 2015;29:383-389.

37 Fallon P, Dursun SM: A naturalistic controlled study of relapsing schizophrenic patients with tardive dyskinesia and supersensitivity psychosis. J Psychopharmacol 2011;25: 755-762.

38 Fallon P, Dursun S, Deakin B: Drug-induced supersensitivity psychosis revisited: characteristics of relapse in treatment-compliant patients. Ther Adv Psychopharmacol 2012;2: $13-22$. 
39 Margolese HC, Chouinard G, Beauclair L, Belanger MC: Therapeutic tolerance and rebound psychosis during quetiapine maintenance monotherapy in patients with schizophrenia and schizoaffective disorder. J Clin Psychopharmacol 2002;22:347-352.

40 Ekblom B, Eriksson K, Lindstrom LH: Supersensitivity psychosis in schizophrenic patients after sudden clozapine withdrawal. Psychopharmacology (Berl) 1984;83:293-294.

41 Chouinard G, Chouinard VA: New classification of selective serotonin reuptake inhibitor withdrawal. Psychother Psychosom 2015;84: 63-71.

42 Sasaki H, Hashimoto K, Maeda Y, Inada T, Kitao Y, Fukui S, Iyo M: Rolipram, a selective c-AMP phosphodiesterase inhibitor suppresses oro-facial dyskinetic movements in rats. Life Sci 1995;56:PL443-PL447.

43 Sasaki H, Hashimoto K, Inada T, Fukui S, Iyo M: Suppression of oro-facial movements by rolipram, a cAMP phosphodiesterase inhibitor, in rats chronically treated with haloperidol. Eur J Pharmacol 1995;282:71-76.

44 Tadokoro S, Okamura N, Sekine Y, Kanahara $\mathrm{N}$, Hashimoto K, Iyo M: Chronic treatment with aripiprazole prevents development of dopamine supersensitivity and potentially supersensitivity psychosis. Schizophr Bull 2012; 38:1012-1020.

45 Lerer B, Jabotinsky-Rubin K, Bannet J, Ebstein RP, Belmaker RH: Electroconvulsive shock prevents dopamine receptor supersensitivity. Eur J Pharmacol 1982;80:131-134.

46 Smith RC, Davis JM: Behavioral evidence for supersensitivity after chronic administration of haloperidol, clozapine, and thioridazine. Life Sci 1976;19:725-731.

47 Turrone P, Remington G, Kapur S, Nobrega JN: The relationship between dopamine D2 receptor occupancy and the vacuous chewing movement syndrome in rats. Psychopharmacology (Berl) 2003;165:166-171.

48 O’Dell SJ, La Hoste GJ, Widmark CB, Shapiro RM, Potkin SG, Marshall JF: Chronic treatment with clozapine or haloperidol differentially regulates dopamine and serotonin receptors in rat brain. Synapse 1990;6:146-153.

49 Wilmot CA, Szczepanik AM: Effects of acute and chronic treatments with clozapine and haloperidol on serotonin $\left(5-\mathrm{HT}_{2}\right)$ and dopamine $\left(D_{2}\right)$ receptors in the rat brain. Brain Res 1989;487:288-298.

50 Ginovart N, Wilson AA, Hussey D, Houle S, Kapur S: $D_{2}$-receptor upregulation is dependent upon temporal course of $\mathrm{D}_{2}$-occupancy: a longitudinal $\left[{ }^{11} \mathrm{C}\right]$-raclopride PET study in cats. Neuropsychopharmacology 2009;34:662-671.

51 Huang N, Ase AR, Hebert C, van Gelder NM, Reader TA: Effects of chronic neuroleptic treatments on dopamine $D_{1}$ and $D_{2}$ receptors: homogenate binding and autoradiographic studies. Neurochem Int 1997;30:277-290.

52 Muller P, Seeman P: Dopaminergic supersensitivity after neuroleptics: time-course and specificity. Psychopharmacology (Berl) 1978; 60:1-11.
53 Marin C, Chase TN: Dopamine $\mathrm{D}_{1}$ receptor stimulation but not dopamine $\mathrm{D}_{2}$ receptor stimulation attenuates haloperidol-induced behavioral supersensitivity and receptor upregulation. Eur J Pharmacol 1993;231:191196.

54 Ase AR, Amdiss F, Hebert C, Huang N, van Gelder NM, Reader TA: Effects of antipsychotic drugs on dopamine and serotonin contents and metabolites, dopamine and serotonin transporters, and serotonin1A receptors. J Neural Transm (Vienna) 1999;106: 75-105.

55 Rivest R, Falardeau P, Di Paolo T: Brain dopamine transporter: gender differences and effect of chronic haloperidol. Brain Res 1995; 692:269-272.

56 Thompson JL, Urban N, Slifstein M, Xu X, Kegeles LS, Girgis RR, Beckerman Y, Harkavy-Friedman JM, Gil R, Abi-Dargham A: Striatal dopamine release in schizophrenia comorbid with substance dependence. Mol Psychiatry 2013;18:909-915.

57 Chesi AJ, Feasey-Truger KJ, Alzheimer C, ten Bruggencate G: Dopamine autoreceptor sensitivity is unchanged in rat nucleus accumbens after chronic haloperidol treatment: an in vivo and in vitro voltammetric study. Eur J Neurosci 1995; 7:2450-2457.

58 Ichikawa J, Meltzer HY: The effect of chronic atypical antipsychotic drugs and haloperidol on amphetamine-induced dopamine release in vivo. Brain Res 1992;574:98-104.

59 Seeman P, Schwarz J, Chen JF, Szechtman H, Perreault M, McKnight GS, Roder JC, Quirion R, Boksa P, Srivastava LK, Yanai K, Weinshenker D, Sumiyoshi T: Psychosis pathways converge via $\mathrm{D}_{2}{ }_{\text {High }}$ dopamine receptors. Synapse 2006;60:319-346.

60 Seeman P, Guan HC: Dopamine partial agonist action of (-)OSU6162 is consistent with dopamine hyperactivity in psychosis. Eur J Pharmacol 2007;557:151-153.

61 Seeman P: Dopamine $\mathrm{D}_{2}{ }^{\text {High }}$ receptors moderately elevated by sertindole. Synapse 2008; 62:389-393.

62 Seeman P: Dopamine $\mathrm{D}_{2}{ }^{\text {High }}$ receptors moderately elevated by bifeprunox and aripiprazole. Synapse 2008;62:902-908.

63 Graff-Guerrero A, Mizrahi R, Agid O, Marcon H, Barsoum P, Rusjan P, Wilson AA, Zipursky R, Kapur S: The dopamine $\mathrm{D}_{2}$ receptors in high-affinity state and $\mathrm{D}_{3}$ receptors in schizophrenia: a clinical $\left[{ }^{11} \mathrm{C}\right]-(+)-\mathrm{PHNO}$ PET study. Neuropsychopharmacology 2009; 34:1078-1086.

64 Seeman P: Dopamine agonist radioligand binds to both $\mathrm{D}_{2}{ }^{\text {High }}$ and $\mathrm{D}_{2}^{\text {Low }}$ receptors, explaining why alterations in $\mathrm{D}_{2}{ }^{\text {High }}$ are not detected in human brain scans. Synapse 2012; 66:88-93.

65 Cho D, Zheng M, Min C, Ma L, Kurose H, Park JH, Kim KM: Agonist-induced endocytosis and receptor phosphorylation mediate resensitization of dopamine $\mathrm{D}_{2}$ receptors. Mol Endocrinol 2010;24:574-586.
66 Rogue P, Hanauer A, Zwiller J, Malviya AN, Vincendon G: Up-regulation of dopamine $\mathrm{D}_{2}$ receptor mRNA in rat striatum by chronic neuroleptic treatment. Eur J Pharmacol 1991; 207:165-168.

67 Oda Y, Tadokoro S, Takase M, Kanahara N, Watanabe H, Shirayama Y, Hashimoto K, Iyo $\mathrm{M}$ : $\mathrm{G}$ protein-coupled receptor kinase $6 / \beta$-arrestin 2 system in a rat model of dopamine supersensitivity psychosis. J Psychopharmacol 2015;29:1308-1313.

68 Oda Y, Kanahara N, Iyo M: Alterations of dopamine $\mathrm{D}_{2}$ receptors and related receptor-interacting proteins in schizophrenia: the pivotal position of dopamine supersensitivity psychosis in treatment-resistant schizophrenia. Int J Mol Sci 2015;16:30144-30163.

69 Chouinard G, Sultan S: Treatment of neuroleptic-induced supersensitivity psychosis with antiepileptic drugs: report of a series of 43 cases. Psychopharmacol Bull 1990;26:337-341.

70 Schooler NR, Kane JM: Research diagnoses for tardive dyskinesia. Arch Gen Psychiatry 1982;39:486-487.

71 Chouinard G, Annable L, Ross-Chouinard A, Mercier P: A 5-year prospective longitudinal study of tardive dyskinesia: factors predicting appearance of new cases. J Clin Psychopharmacol 1988;8:21S-26S.

72 Chouinard G, Annable L, Ross-Chouinard A: Supersensitivity psychosis and tardive dyskinesia: a survey in schizophrenic outpatients. Psychopharmacol Bull 1986;22:891-896.

73 Chouinard G, Miller R: A Rating Scale for Psychotic Symptoms (RSPS) part I: theoretical principles and subscale 1: perception symptoms (illusions and hallucinations). Schizophr Res 1999;38:101-122.

74 Chouinard G, Miller R: A Rating Scale for Psychotic Symptoms (RSPS): part II: subscale 2: distraction symptoms (catatonia and passivity experiences subscale 3 : delusions and semi-structured interview (SSCI-RSPS) Schizophr Res 1999;38:123-150.

75 Juarez-Reyes MG, Shumway M, Battle C, Bacchetti P, Hansen MS, Hargreaves WA: Clozapine eligibility: the effect of stringent criteria on ethnic, gender and age subgroups of schizophrenic patients. Prog Neuropsychopharmacol Biol Psychiatry 1996;20:1341-1352.

76 Juarez-Reyes MG, Shumway M, Battle C, Bacchetti P, Hansen MS, Hargreaves WA: Effects of stringent criteria on eligibility for clozapine among public mental health clients. Psychiatr Serv 1995;46:801-806

77 Carpenter WT Jr, Heinrichs DW, Wagman AM: Deficit and nondeficit forms of schizophrenia: the concept. Am J Psychiatry 1988; 145:578-583.

78 Kolalowska T: Brief Psychiatric Rating Scale. Glossaries and Rating Instructions. Oxford, Oxford University, 1976

79 Inada T: Recent research trends in diagnosis, treatment, and prevention of drug-induced extrapyramidal symptoms seen in psychiatric patients (in Japanese). Nihon Shinkei Seishin Yakurigaku Zasshi 1996;16:181-185. 
80 Inada T, Inagaki A: Psychotropic dose equivalence in Japan. Psychiatry Clin Neurosci 2015;69:440-447.

81 Chouinard G, Margolese HC: Manual for the Extrapyramidal Symptom Rating Scale (ESRS). Schizophr Res 2005;76:247-265.

82 Chouinard G, Ross-Chouinard A, Annable L, Jones BD: Extrapyramidal symptom rating scale. Can J Neurol Sci 1980;7:233.

83 Overall J, Gorham DR: The Brief Psychiatric Rating Scale. Psychol Rep 1962;10:799-812.

84 Kimura H, Kanahara N, Sasaki T, Komatsu N, Ishige $\mathrm{M}$, Muneoka $\mathrm{K}$, Ino $\mathrm{H}$, Yoshimura $\mathrm{K}$, Yamanaka H, Suzuki T, Komatsu H, Watanabe H, Shimizu E, Iyo M: Risperidone longacting injectable in the treatment of treatment-resistant schizophrenia with dopamine supersensitivity psychosis: results of a 2-year prospective study, including an additional 1-year follow-up. J Psychopharmacol 2016; 30:795-802.

85 Wing J, Cooper JE, Sartorius N: Measurement and Classification of Psychiatric Symptoms. Cambridge, Cambridge University Press, 1974.

86 Guy W: ECDEU Assessment Manual for Psychopharmacology, revised. Washington, US Department of Health, Education, and Welfare, 1976.

87 Brown GW, Harris T: Social Origins of Depression: A Study of Psychiatric Disorder in Women. London, Tavistock, 1978.

88 Fallon P: The role of intrusive and other recent life events on symptomatology in relapses of schizophrenia: a community nursing investigation. J Psychiatr Ment Health Nurs 2009;16:685-693.

89 Chouinard G: Rebound anxiety: incidence and relationship to subjective cognitive impairment. J Clin Psychiatry Monograph 1986; $4: 12-16$.

90 Chouinard G: Issues in the clinical use of benzodiazepines: potency, withdrawal, and rebound. J Clin Psychiatry 2004;65(suppl 5):7-12.

91 Fava GA, Gatti A, Belaise C, Guidi J, Offidani E: Withdrawal symptoms after selective serotonin reuptake inhibitor discontinuation: a systematic review. Psychother Psychosom 2015;84:72-81.

92 Schatzberg AF, Blier P, Delgado PL, Fava M, Haddad PM, Shelton RC: Antidepressant discontinuation syndrome: consensus panel recommendations for clinical management and additional research. J Clin Psychiatry 2006; 67(suppl 4):27-30.

93 Tranter R, Healy D: Neuroleptic discontinuation syndromes. J Psychopharmacol 1998;12: 401-406.

94 Cerovecki A, Musil R, Klimke A, Seemuller F, Haen E, Schennach R, Kuhn KU, Volz HP, Riedel M: Withdrawal symptoms and rebound syndromes associated with switching and discontinuing atypical antipsychotics: theoretical background and practical recommendations. CNS Drugs 2013;27:545-572.
95 Brower KJ: Alcohol's effects on sleep in alcoholics. Alcohol Res Health 2001;25:110-125.

96 Shammash JB, Trost JC, Gold JM, Berlin JA, Golden MA, Kimmel SE: Perioperative betablocker withdrawal and mortality in vascular surgical patients. Am Heart J 2001;141: 148-153.

97 Stevenson E, Schembri F, Green DM, Burns JD: Serotonin syndrome associated with clozapine withdrawal. JAMA Neurol 2013;70: 1054-1055.

$98 \mathrm{Hu}$ WW, Fang Q, Xu ZH, Yan HJ, He P, Zhong K, Fan YY, Yang Y, Zhang XN, Zhang CY, Ohtsu H, Xu TL, Chen Z: Chronic H1antihistamine treatment increases seizure susceptibility after withdrawal by impairing glutamine synthetase. CNS Neurosci Ther 2012;18:683-690.

99 Nattel S, Rangno RE, Van Loon G: Mechanism of propranolol withdrawal phenomena. Circulation 1979;59:1158-1164.

100 Luchins DJ, Freed WJ, Wyatt RJ: The role of cholinergic supersensitivity in the medical symptoms associated with withdrawal of antipsychotic drugs. Am J Psychiatry 1980;137: 1395-1398.

101 Shiovitz TM, Welke TL, Tigel PD, Anand R, Hartman RD, Sramek JJ, Kurtz NM, Cutler NR: Cholinergic rebound and rapid onset psychosis following abrupt clozapine withdrawal. Schizophr Bull 1996;22:591-595.

102 Houston MC, Hodge R: Beta-adrenergic blocker withdrawal syndromes in hypertension and other cardiovascular diseases. Am Heart J 1988;116:515-523.

103 Fontaine R, Chouinard G, Annable L: Rebound anxiety in anxious patients after abrupt withdrawal of benzodiazepine treatment. Am J Psychiatry 1984;141:848-852.

104 Kales A, Bixler EO, Tan TL, Scharf MB, Kales JD: Chronic hypnotic-drug use. Ineffectiveness, drug-withdrawal insomnia, and dependence. JAMA 1974;227:513-517.

105 Kales A, Scharf MB, Kales JD: Rebound insomnia: a new clinical syndrome. Science 1978;201:1039-1041.

106 Oswald I, Priest RG: Five weeks to escape the sleeping-pill habit. Br Med J 1965;2:10931095.

107 Kales A, Preston TA, Tan TL, Allen C: Hypnotics and altered sleep-dream patterns. I. All-night EEG studies of glutethimide, methyprylon, and pentobarbital. Arch Gen Psychiatry 1970;23:211-218.

108 Miller RR, Olson HG, Amsterdam EA, Mason DT: Propranolol-withdrawal rebound phenomenon. Exacerbation of coronary events after abrupt cessation of antianginal therapy. N Engl J Med 1975;293:416-418.

109 Bhanji NH, Chouinard G, Kolivakis T, Margolese HC: Persistent tardive rebound panic disorder, rebound anxiety and insomnia following paroxetine withdrawal: a review of rebound-withdrawal phenomena. Can J Clin Pharmacol 2006;13:e69-e74.
110 Rosenbaum JF, Fava M, Hoog SL, Ascroft RC, Krebs WB: Selective serotonin reuptake inhibitor discontinuation syndrome: a randomized clinical trial. Biol Psychiatry 1998; 44:77-87.

111 Michelson D, Fava M, Amsterdam J, Apter J, Londborg P, Tamura R, Tepner RG: Interruption of selective serotonin reuptake inhibitor treatment. Double-blind, placebocontrolled trial. Br J Psychiatry 2000;176: 363-368.

112 Cloos JM, Bocquet V, Rolland-Portal I, Koch P, Chouinard G: Hypnotics and triazolobenzodiazepines - best predictors of high-dose benzodiazepine use: results from the Luxembourg National Health Insurance Registry. Psychother Psychosom 2015;84:273283.

113 Mendelson JH, Mello NK: Management of cocaine abuse and dependence. $\mathrm{N}$ Engl J Med 1996;334:965-972.

114 Kosten TR, O'Connor PG: Management of drug and alcohol withdrawal. N Engl J Med 2003;348:1786-1795.

115 Markowitz JS, Brown CS, Moore TR: Atypical antipsychotics. Part I: Pharmacology, pharmacokinetics, and efficacy. Ann Pharmacother 1999;33:73-85.

116 Kapur S, Seeman P: Does fast dissociation from the dopamine $\mathrm{D}_{2}$ receptor explain the action of atypical antipsychotics? A new hypothesis. Am J Psychiatry 2001;158:360369.

117 Bandelow B, Chouinard G, Bobes J, Ahokas A, Eggens I, Liu S, Eriksson H: Extendedrelease quetiapine fumarate (quetiapine $\mathrm{XR}$ ): a once-daily monotherapy effective in generalized anxiety disorder. Data from a randomized, double-blind, placebo- and active-controlled study. Int J Neuropsychopharmacol 2010;13:305-320.

118 Sanford M: Quetiapine extended release: adjunctive treatment in major depressive disorder. CNS Drugs 2011;25:803-813.

119 Mamo DC, Uchida H, Vitcu I, Barsoum P, Gendron A, Goldstein J, Kapur S: Quetiapine extended-release versus immediate-release formulation: a positron emission tomography study. J Clin Psychiatry 2008;69: 81-86.

120 Seeman P, Tallerico T: Rapid release of antipsychotic drugs from dopamine $D_{2}$ receptors: an explanation for low receptor occupancy and early clinical relapse upon withdrawal of clozapine or quetiapine. Am J Psychiatry 1999;156:876-884.

121 Burki HR: Effects of fluperlapine on dopaminergic systems in rat brain. Psychopharmacology (Berl) 1986;89:77-84.

122 Kapur S, Zipursky R, Jones C, Shammi CS, Remington G, Seeman P: A positron emission tomography study of quetiapine in schizophrenia: a preliminary finding of an antipsychotic effect with only transiently high dopamine $\mathrm{D}_{2}$ receptor occupancy. Arch Gen Psychiatry 2000;57:553-559. 
123 Rangno RE, Nattel S, Lutterodt A: Prevention of propranolol withdrawal mechanism by prolonged small dose propranolol schedule. Am J Cardiol 1982;49:828-833.

124 Rangno RE, Langlois S: Comparison of withdrawal phenomena after propranolol, metoprolol and pindolol. Br J Clin Pharmacol 1982;13:345S-351S.

125 Gilligan DM, Chan WL, Stewart R, Oakley CM: Adrenergic hypersensitivity after betablocker withdrawal in hypertrophic cardiomyopathy. Am J Cardiol 1991;68:766-772.

126 Ashton H: Protracted withdrawal syndromes from benzodiazepines. J Subst Abuse Treat 1991;8:19-28.

127 Fava GA, Bernardi M, Tomba E, Rafanelli C: Effects of gradual discontinuation of selective serotonin reuptake inhibitors in panic disorder with agoraphobia. Int J Neuropsychopharmacol 2007;10:835-838.

128 Belaise C, Gatti A, Chouinard VA, Chouinard G: Patient online report of selective serotonin reuptake inhibitor-induced persistent postwithdrawal anxiety and mood disorders. Psychother Psychosom 2012;81: 386-388.

129 Belaise C, Gatti A, Chouinard VA, Chouinard G: Persistent postwithdrawal disorders induced by paroxetine, a selective serotonin reuptake inhibitor, and treated with specific cognitive behavioral therapy. Psychother Psychosom 2014;83:247-248.

130 Shoenberger D: Discontinuing paroxetine: a personal account. Psychother Psychosom 2002;71:237-238.

131 Chouinard G, Annable L, Ross-Chouinard A, Nestoros JN: Factors related to tardive dyskinesia. Am J Psychiatry 1979;136:7982.

132 Christensen AV, Fjalland B, Nielsen IM: On the supersensitivity of dopamine receptors, induced by neuroleptics. Psychopharmacology (Berl) 1976;48:1-6.

133 Chouinard G, Jones BD: Early onset of tardive dyskinesia: case report. Am J Psychiatry 1979;136:1323-1324.

134 Chouinard G, Boisvert D, Bradwejn J: Tardive dyskinesia in a nonpsychiatric patient due to short-term use of a neuroleptic/anticholinergic combination drug. Can Med Assoc J 1982;126:821-822, 827.

135 Tarazi FI, Zhang K, Baldessarini RJ: Longterm effects of olanzapine, risperidone, and quetiapine on dopamine receptor types in regions of rat brain: implications for antipsychotic drug treatment. J Pharmacol Exp Ther 2001;297:711-717.

136 Kusumi I, Takahashi Y, Suzuki K, Kameda K, Koyama T: Differential effects of subchronic treatments with atypical antipsychotic drugs on dopamine $\mathrm{D}_{2}$ and serotonin $5-\mathrm{HT}_{2 \mathrm{~A}}$ receptors in the rat brain. J Neural Transm (Vienna) 2000;107:295-302.
137 Brunelin J, d'Amato T, Van Os J, Costes N, Suaud Chagny MF, Saoud M: Increased left striatal dopamine transmission in unaffected siblings of schizophrenia patients in response to acute metabolic stress. Psychiatry Res 2010;181:130-135.

138 Kapur S, Zipursky R, Jones C, Remington G, Houle S: Relationship between dopamine $\mathrm{D}_{2}$ occupancy, clinical response, and side effects: a double-blind PET study of first-episode schizophrenia. Am J Psychiatry 2000; 157:514-520

139 Gardos G, Cole JO, Tarsy D: Withdrawal syndromes associated with antipsychotic drugs. Am J Psychiatry 1978;135:13211324.

140 Kimura H, Kanahara N, Watanabe H, Iyo M: Potential treatment strategy of risperidone in long-acting injectable form for schizophrenia with dopamine supersensitivity psychosis. Schizophr Res 2013;145:130-131.

141 Wadenberg ML, Kapur S, Soliman A, Jones C, Vaccarino F: Dopamine $\mathrm{D}_{2}$ receptor occupancy predicts catalepsy and the suppression of conditioned avoidance response behavior in rats. Psychopharmacology (Berl) 2000;150:422-429.

142 Natesan S, Reckless GE, Nobrega JN, Fletcher PJ, Kapur S: Dissociation between in vivo occupancy and functional antagonism of dopamine D2 receptors: comparing aripiprazole to other antipsychotics in animal models. Neuropsychopharmacology 2006; 31:1854-1863

143 Van Putten T, May RP: "Akinetic depression" in schizophrenia. Arch Gen Psychiatry 1978;35:1101-1107.

144 Rifkin A, Quitkin F, Klein DF: Akinesia: a poorly recognized drug-induced extrapyramydal behavioral disorder. Arch Gen Psychiatry 1975;32:672-674.

145 Voruganti LP, Awad AG: Is neuroleptic dysphoria a variant of drug-induced extrapyramidal side effects? Can J Psychiatry 2004;49: 285-289.

146 Margolese HC, Chouinard G, Walters Larach V, Beauclair L: Relationship between antipsychotic-induced akathisia and tardive dyskinesia and suicidality in schizophrenia: impact of clozapine and olanzapine. Acta Psychiatr Belg 2001;101:128-144.

147 Van Putten T, Mutalipassi LR, Malkin MD: Phenothiazine-induced decompensation. Arch Gen Psychiatry 1974;30:102-105.

148 Takeuchi H, Suzuki T, Uchida H, Watanabe K, Mimura M: Antipsychotic treatment for schizophrenia in the maintenance phase: a systematic review of the guidelines and algorithms. Schizophr Res 2012;134:219-225.

149 Valenti O, Cifelli P, Gill KM, Grace AA: Antipsychotic drugs rapidly induce dopamine neuron depolarization block in a developmental rat model of schizophrenia. J Neurosci $2011 ; 31: 12330-12338$.
150 Benet LZ, Zia-Amirhosseini P: Basic principles of pharmacokinetics. Toxicol Pathol 1995;23:115-123.

151 Sheehan JJ, Reilly KR, Fu DJ, Alphs L: Comparison of the peak-to-trough fluctuation in plasma concentration of long-acting injectable antipsychotics and their oral equivalents. Innov Clin Neurosci 2012;9:17-23.

152 Piafsky KM: Disease-induced changes in the plasma binding of basic drugs. Clin Pharmacokinet 1980;5:246-262.

153 Lee LH, Choi C, Collier AC, Barr AM, Honer WG, Procyshyn RM: The pharmacokinetics of second-generation long-acting injectable antipsychotics: limitations of monograph values. CNS Drugs 2015;29:975-983.

154 Ericson H, Radesater AC, Servin E, Magnusson $\mathrm{O}$, Mohringe B: Effects of intermittent and continuous subchronic administration of raclopride on motor activity, dopamine turnover and receptor occupancy in the rat. Pharmacol Toxicol 1996;79:277-286.

155 Smith RC, Davis JM: Behavioral supersensitivity to apomorphine and amphetamine after chronic high dose haloperidol treatment. Psychopharmacol Commun 1975;1:285293.

156 Fukushiro DF, Carvalho Rde C, Ricardo VP, Alvarez Jdo N, Ribeiro LT, Frussa-Filho R: Haloperidol (but not ziprasidone) withdrawal potentiates sensitization to the hyperlocomotor effect of cocaine in mice. Brain Res Bull 2008;77:124-128.

157 Carvalho RC, Fukushiro DF, Helfer DC, Callegaro-Filho D, Trombin TF, Zanlorenci LH, Sanday L, Silva RH, Frussa-Filho R: Long-term haloperidol treatment (but not risperidone) enhances addiction-related behaviors in mice: role of dopamine $\mathrm{D}_{2}$ receptors. Addict Biol 2009;14:283-293.

158 Montanaro N, Dall'Olio R, Gandolfi O, Vaccheri A: Differential enhancement of behavioral sensitivity to apomorphine following chronic treatment of rats with (-)-sulpiride and haloperidol. Eur J Pharmacol 1982;81: 1-9.

159 Kapur S, VanderSpek SC, Brownlee BA, Nobrega JN: Antipsychotic dosing in preclinical models is often unrepresentative of the clinical condition: a suggested solution based on in vivo occupancy. J Pharmacol Exp Ther 2003;305:625-631.

160 McCreadie RG, Dingwall JM, Wiles DH, Heykants JJ: Intermittent pimozide versus fluphenazine decanoate as maintenance therapy in chronic schizophrenia. Br J Psychiatry 1980;137:510-517.

161 Remington G, Seeman P, Feingold A, Mann S, Shammi C, Kapur S: "Extended" antipsychotic dosing in the maintenance treatment of schizophrenia: a double-blind, placebocontrolled trial. J Clin Psychiatry 2011;72: 1042-1048. 
162 Tsuboi T, Suzuki T, Bies RR, Remington G, Pollock BG, Mimura M, Uchida H: Challenging the need for sustained blockade of dopamine $\mathrm{D}_{2}$ receptor estimated from antipsychotic plasma levels in the maintenance treatment of schizophrenia: a single-blind, randomized, controlled study. Schizophr Res 2015;164:149-154.

163 Nyberg S, Farde L, Halldin C, Dahl ML, Bertilsson $\mathrm{L}: \mathrm{D}_{2}$ dopamine receptor occupancy during low-dose treatment with haloperidol decanoate. Am J Psychiatry 1995;152:173178.

164 Uchida H, Suzuki T: Dose and dosing frequency of long-acting injectable antipsychotics: a systematic review of PET and SPECT data and clinical implications. J Clin Psychopharmacol 2014;34:728-735.

165 Samaha AN: Can antipsychotic treatment contribute to drug addiction in schizophrenia? Prog Neuropsychopharmacol Biol Psychiatry 2014;52:9-16.

166 Samaha AN, Potvin S: Drugs of abuse and psychiatric disorders: neurobiological and clinical aspects. Prog Neuropsychopharmacol Biol Psychiatry 2014;52:1-3.

167 Correll CU, Leucht S, Kane JM: Lower risk for tardive dyskinesia associated with second-generation antipsychotics: a systematic review of 1-year studies. Am J Psychiatry 2004;161:414-425.

168 Li Z, Ichikawa J, Huang M, Prus AJ, Dai J, Meltzer HY: ACP-103, a 5- $\mathrm{HT}_{2 \mathrm{~A} / 2 \mathrm{C}}$ inverse agonist, potentiates haloperidol-induced dopamine release in rat medial prefrontal cortex and nucleus accumbens. Psychopharmacology (Berl) 2005;183:144-153.

169 Chouinard G: Effects of risperidone in tardive dyskinesia: an analysis of the Canadian multicenter risperidone study. J Clin Psychopharmacol 1995;15:36S-44S.

170 Kane JM, Honigfeld G, Singer J, Meltzer H: Clozapine in treatment-resistant schizophrenics. Psychopharmacol Bull 1988;24: 62-67.

171 Seeman P, Lee T, Chau-Wong M, Wong K: Antipsychotic drug doses and neuroleptic/ dopamine receptors. Nature 1976;261:717719.

172 Seeman P: Dopamine $\mathrm{D}_{2}$ receptors as treatment targets in schizophrenia. Clin Schizophr Relat Psychoses 2010;4:56-73.

173 Goldstein J, Macfadden W: Reply to article by Margolese and associates on tolerance and rebound during maintenance with quetiapine. J Clin Psychopharmacol 2004;24: 102-103; author reply 103-104.

174 Meltzer HY, Alphs L, Green AI, Altamura AC, Anand R, Bertoldi A, Bourgeois M, Chouinard G, Islam MZ, Kane J, Krishnan R, Lindenmayer JP, Potkin S: Clozapine treatment for suicidality in schizophrenia: International Suicide Prevention Trial (InterSePT). Arch Gen Psychiatry 2003;60:8291.
175 Fukushiro DF, Alvarez Jdo N, Tatsu JA, de Castro JP, Chinen CC, Frussa-Filho R: Haloperidol (but not ziprasidone) withdrawal enhances cocaine-induced locomotor activation and conditioned place preference in mice. Prog Neuropsychopharmacol Biol Psychiatry 2007;31:867-872.

176 Creese I, Snyder SH: Chronic neuroleptic treatment and dopamine receptor regulation. Adv Biochem Psychopharmacol 1980; 24:89-94.

177 Severson JA, Robinson HE, Simpson GM: Neuroleptic-induced striatal dopamine receptor supersensitivity in mice: relationship to dose and drug. Psychopharmacology (Berl) 1984;84:115-119.

178 Seeman P, Corbett R, Van Tol HH: Atypical neuroleptics have low affinity for dopamine $D_{2}$ receptors or are selective for $D_{4}$ receptors. Neuropsychopharmacology 1997; 16: 93 110; discussion 111-135.

179 Meltzer HY, Matsubara S, Lee JC: The ratios of serotonin2 and dopamine 2 affinities differentiate atypical and typical antipsychotic drugs. Psychopharmacol Bull 1989;25:390392.

180 Urban JD, Clarke WP, von Zastrow M, Nichols DE, Kobilka B, Weinstein H, Javitch JA, Roth BL, Christopoulos A, Sexton PM, Miller KJ, Spedding M, Mailman RB: Functional selectivity and classical concepts of quantitative pharmacology. J Pharmacol Exp Ther 2007;320:1-13.

181 de Bartolomeis A, Tomasetti C, Iasevoli F: Update on the mechanism of action of aripiprazole: translational insights into antipsychotic strategies beyond dopamine receptor antagonism. CNS Drugs 2015;29: 773-799.

182 Urban JD, Vargas GA, von Zastrow M, Mailman RB: Aripiprazole has functionally selective actions at dopamine $\mathrm{D}_{2}$ receptor-mediated signaling pathways. Neuropsychopharmacology 2007;32:67-77.

183 Burris KD, Molski TF, Xu C, Ryan E, Tottori K, Kikuchi T, Yocca FD, Molinoff PB: Aripiprazole, a novel antipsychotic, is a high-affinity partial agonist at human dopamine $\mathrm{D}_{2}$ receptors. J Pharmacol Exp Ther 2002;302:381-389.

184 Di Lorenzo R, Amoretti A, Forghieri M, Fiorini F, Genedani S, Rigatelli M: Aripiprazole: effectiveness and safety under naturalistic conditions. Exp Clin Psychopharmacol 2007;15:569-575.

185 Marder SR, McQuade RD, Stock E, Kaplita S, Marcus R, Safferman AZ, Saha A, Ali $\mathrm{M}$, Iwamoto T: Aripiprazole in the treatment of schizophrenia: safety and tolerability in short-term, placebo-controlled trials. Schizophr Res 2003;61:123-136.

186 Gorwood P: Meeting everyday challenges: antipsychotic therapy in the real world. Eur Neuropsychopharmacol 2006;16(suppl 3): S156-S162.
187 Ishigooka J, Nakamura J, Fujii Y, Iwata N, Kishimoto T, Iyo M, Uchimura N, Nishimura R, Shimizu N, Group AS: Efficacy and safety of aripiprazole once-monthly in Asian patients with schizophrenia: a multicenter, randomized, double-blind, non-inferiority study versus oral aripiprazole. Schizophr Res 2015;161:421-428.

188 Sultan S, Chouinard G, Beaudry P: Antiepileptic drugs in the treatment of neurolepticinduced supersensitivity psychosis. Prog Neuropsychopharmacol Biol Psychiatry 1990;14:431-438.

189 Goddard GV, McIntyre DC, Leech CK: A permanent change in brain function resulting from daily electrical stimulation. Exp Neurol 1969;25:295-330.

190 Moskovitz C, Moses H 3rd, Klawans HL: Levodopa-induced psychosis: a kindling phenomenon. Am J Psychiatry 1978;135:669675.

191 Post RM, Kopanda RT, Black KE: Progressive effects of cocaine on behavior and central amine metabolism in rhesus monkeys: relationship to kindling and psychosis. Biol Psychiatry 1976;11:403-419.

192 Chouinard G, Beauclair L, Belanger MC: Gabapentin: long-term antianxiety and hypnotic effects in psychiatric patients with comorbid anxiety-related disorders. Can J Psychiatry 1998;43:305.

193 Kolivakis TT, Beauclair L, Margolese HC, Chouinard G: Long-term lamotrigine adjunctive to antipsychotic monotherapy in schizophrenia: further evidence. Can J Psychiatry 2004;49:280.

194 Chouinard G, Vainer JL, Belanger MC Turnier L, Beaudry P, Roy JY, Miller R: Risperidone and clozapine in the treatment of drug-resistant schizophrenia and neuroleptic-induced supersensitivity psychosis. Prog Neuropsychopharmacol Biol Psychiatry 1994;18:1129-1141.

195 Kristensen D, Hageman I, Bauer J, Jorgensen $\mathrm{MB}$, Correll CU: Antipsychotic polypharmacy in a treatment-refractory schizophrenia population receiving adjunctive treatment with electroconvulsive therapy. J ECT 2013;29:271-276

196 McGarvey KA, Zis AP, Brown EE, Nomikos GG, Fibiger HC: ECS-induced dopamine release: effects of electrode placement, anticonvulsant treatment, and stimulus intensity. Biol Psychiatry 1993;34:152-157.

197 Nakata Y, Kanahara N, Kimura H, Watanabe $\mathrm{H}$, Iyo M: Efficacy of clozapine on dopamine supersensitivity psychosis in schizophrenia. Int Clin Psychopharmacol 2017;32: 169-173.

198 Louzã MR, Bassitt DP: Maintenance treatment of severe tardive dyskinesia with clozapine: 5 years' follow-up. J Clin Psychopharmacol 2005;25:180-182.

199 Weber J, McCormack PL: Asenapine. CNS Drugs 2009;23:781-792. 
200 Shahid M, Walker GB, Zorn SH, Wong EH: Asenapine: a novel psychopharmacologic agent with a unique human receptor signature. J Psychopharmacol 2009;23:6573.

201 Rajkumar RP: Supersensitivity psychosis and its response to asenapine in a patient with delusional disorder. Case Rep Psychiatry 2014;2014:215732.

202 Matteo P, Mula M, Basaglia C, Favaretto E, Schwitzer J: Asenapine after clozapine: is possible? Eur Psychiatry 2013;28:1.

203 UpToDate: Asenapine: Drug Information. Alphen aan den Rijn, Wolters Kluwer, 2017.

204 Kokare CK, Tagalpallewar AA, Aragade PS, Bagul US, Bacchav RK, Nanjwade BK: Formulation, evaluation and optimization of asenapine maleate fast mouth dissolving film. J Pharm Sci Pharmacol 2015;2:194207.

205 Huang M, Kwon S, Oyamada Y, Rajagopal L, Miyauchi M, Meltzer HY: Dopamine $\mathrm{D}_{3}$ receptor antagonism contributes to blonanserin-induced cortical dopamine and acetylcholine efflux and cognitive improvement. Pharmacol Biochem Behav 2015;138:49-57.

206 Huang M, Panos JJ, Kwon S, Oyamada Y, Rajagopal L, Meltzer HY: Comparative effect of lurasidone and blonanserin on cortical glutamate, dopamine, and acetylcholine efflux: role of relative serotonin $(5-\mathrm{HT})_{2 \mathrm{~A}}$ and $\mathrm{DA} \mathrm{D}_{2}$ antagonism and $5-\mathrm{HT}_{1 \mathrm{~A}}$ partial agonism. J Neurochem 2014;128:938-949.

207 Tachibana M, Niitsu T, Watanabe M, Hashimoto T, Kanahara N, Ishikawa M, Iyo M: Effectiveness of blonanserin for patients with drug treatment-resistant schizophrenia and dopamine supersensitivity: a retrospective analysis. Asian J Psychiatr 2016;24:28-32.
208 Inoue T, Osada K, Tagawa M, Ogawa $\mathrm{Y}$, Haga T, Sogame Y, Hashizume T, Watanabe T, Taguchi A, Katsumata T, Yabuki M, Yamaguchi N: Blonanserin, a novel atypical antipsychotic agent not actively transported as substrate by P-glycoprotein. Prog Neuropsychopharmacol Biol Psychiatry 2012;39: 156-162.

209 Chouinard G, Annable L, Ross-Chouinard A, Holobow N: A ten-year follow-up of supersensitivity psychosis. Biol Psychiatry 1990;27:110A

210 Margolese HC, Chouinard G, Kolivakis TT, Beauclair L, Miller R: Tardive dyskinesia in the era of typical and atypical antipsychotics. Part 1: pathophysiology and mechanisms of induction. Can J Psychiatry 2005;50:541547.

211 Margolese HC, Chouinard G, Kolivakis TT, Beauclair L, Miller R, Annable L: Tardive dyskinesia in the era of typical and atypical antipsychotics. Part 2: incidence and management strategies in patients with schizophrenia. Can J Psychiatry 2005;50:703-714.

212 de Montigny C, Chouinard G, Annable L: Ineffectiveness of deanol in tardive dyskinesia: a placebo controlled study. Psychopharmacology (Berl) 1979;65:219-223.

213 Chouinard G, De Montigny C, Annable L: Tardive dyskinesia and antiparkinsonian medication. Am J Psychiatry 1979;136:228229.

214 Dyer C: European court upholds UK ban on Halcion. BMJ 1999;318:418.
215 Schooler N, Rabinowitz J, Davidson M, Emsley R, Harvey PD, Kopala L, McGorry PD, Van Hove I, Eerdekens M, Swyzen W, De Smedt G; Early Psychosis Global Working Group: Risperidone and haloperidol in first-episode psychosis: a long-term randomized trial. Am J Psychiatry 2005;162: 947-953.

216 Furberg CD, Pitt B: Withdrawal of cerivastatin from the world market. Curr Control Trials Cardiovasc Med 2001;2:205-207.

217 Chouinard VA, Pingali SM, Chouinard G, Henderson DC, Mallya SG, Cypess AM, Cohen BM, Ongur D: Factors associated with overweight and obesity in schizophrenia, schizoaffective and bipolar disorders. Psychiatry Res 2016;237:304-310.

218 McGuinness SM, Johansson R, Lundstrom J, Ross D: Induction of apoptosis by remoxipride metabolites in HL60 and CD34+/ CD19- human bone marrow progenitor cells: potential relevance to remoxipride-induced aplastic anemia. Chem Biol Interact 1999; 121:253-265.

219 Glassman AH, Bigger JT Jr: Antipsychotic drugs: prolonged QTc interval, torsade de pointes, and sudden death. Am J Psychiatry 2001;158:1774-1782.

220 Roden DM: Drug-induced prolongation of the QT interval. N Engl J Med 2004;350: 1013-1022.

221 Isbister GK, Murray L, John S, Hackett LP, Haider T, O'Mullane P, Gosselin S, Daly F: Amisulpride deliberate self-poisoning causing severe cardiac toxicity including QT prolongation and torsades de pointes. Med J Aust 2006; 184:354-356.

222 Leucht S, Cipriani A, Spineli L, Mavridis D, Orey D, Richter F, Samara M, Barbui C, Engel RR, Geddes JR, Kissling W, Stapf MP, Lassig B, Salanti G, Davis JM: Comparative efficacy and tolerability of 15 antipsychotic drugs in schizophrenia: a multiple-treatments metaanalysis. Lancet 2013;382:951-962. 